\title{
مفهوم التكامل المعرفي وعلاقته بحركة إسلامية المعرفة
}

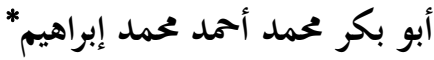

مقدمة:

لقد تنبه المسلمون منذ بدأ اتصالهم بالغرب الحديث إلى التأخر الذي أصاعم، وإلى السبق الحضاري

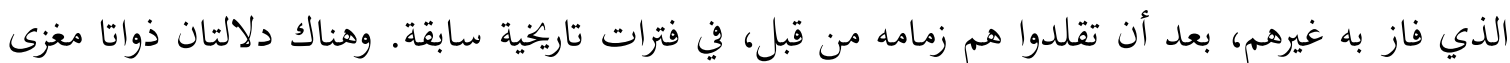

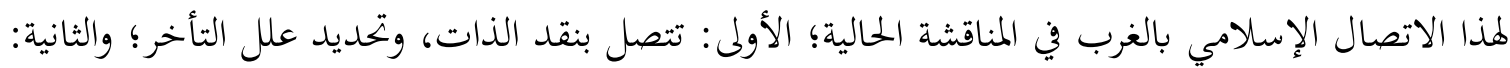

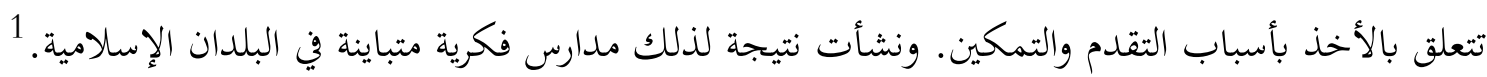

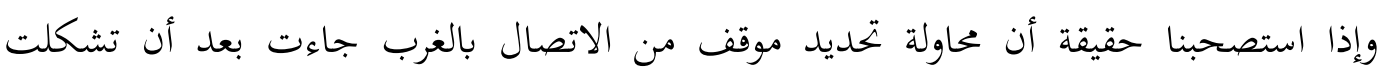

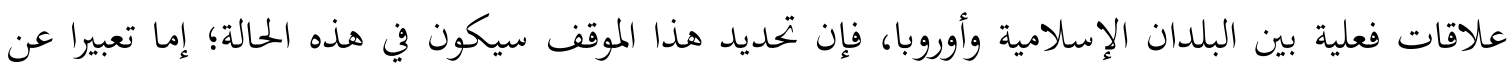

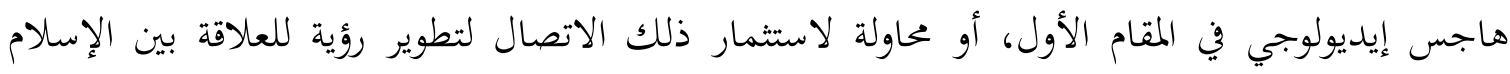

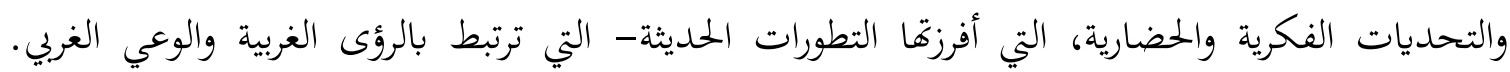

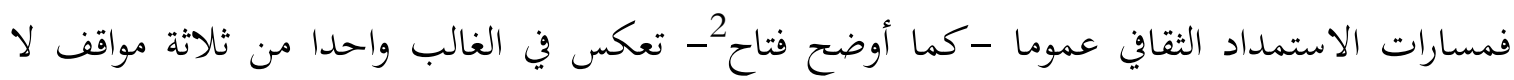
سبيل للتوفيق بينها، وهي: موقف الرفض المطلق للآخر الغريب وثقافته؛ وموقف الانصهار التام المطلق -بلا

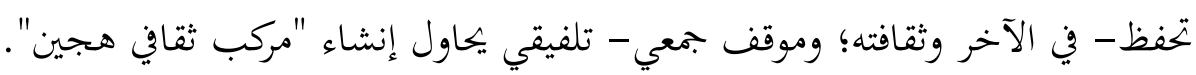

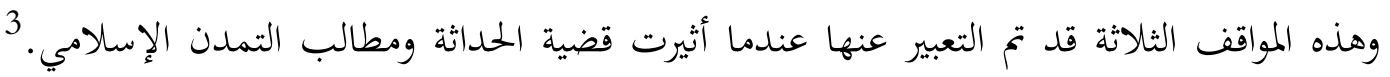

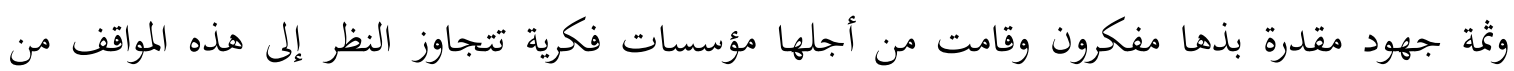

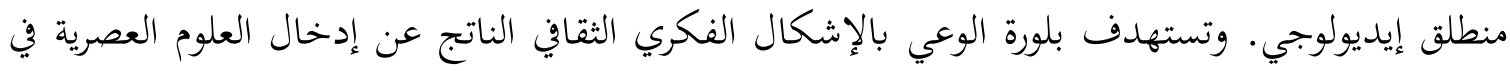

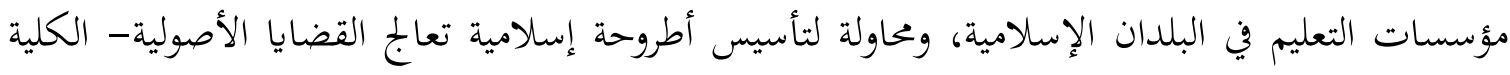
المتصلة بقضايا التنمية والنهوض في هذه البلدان.

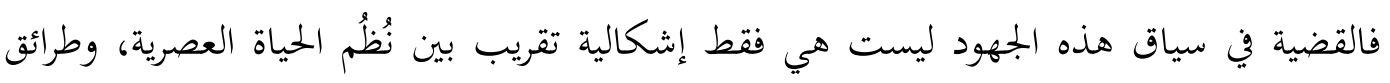

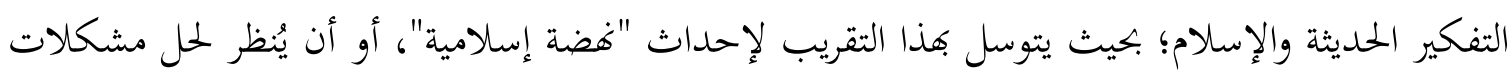

\footnotetext{
أستاذ مساعد ورئيس قسم البحوث بععهد إسلامية المعرفة بجامعة الجزيرة بالسودان، دكتوراه في التربية (مناهج وطرق تدريس) من الجامعة * لyahoo.com.

انظر أهم أطروحات النهضة في العالم الإسلامي ودراسة حوراين التالية: 1
}

Haurani, Albert, Arabic Thought in the liberal Age 1798 -1939, Cambridge: Cambridge University Press, 1983.

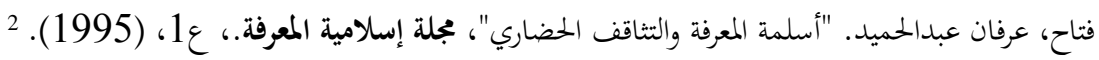

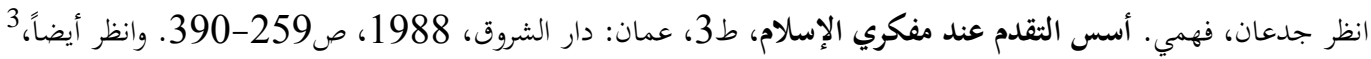

Safi, Louay M., the Challenge of Modernity: the Quest for Authenticity in the Arab world, University Press of America, (Lanham- New York- London), Pp. 111 - 172. 
المسلمين في عصرهم الحديث بمنطق الأمير شكيب أرسلان: "المسلمون ينهضون بمثل ما فض به غيرهم". ذلك أن الحديث عن تخلف المسلمين قياسا على تقدم غيرهم لا يفسر الأزمة التي يعيشها المسلمون في كل جوانبها، ولا الأزمة الإنسانية العامة؛ لا سيما وأن التأخر الذي أصاب المسلمين لم يكن بسبب دينهم، كما أن التقدم المادي الذي شهده الغرب في عصوره المتأخرة لم يكن بسبب ردة دينية بالمفهوم الديني الخالص.5 وإن كانت هذه هي العِلة التي ألفها كثير من قُراء تاريخ العلم في الفكر الغربي، وقبلوها دون مناقشة. وثمة رأيٌّ يقول بأن التجربة الإسلامية -ولأسباب تاريخية عدة- آلت إلى التضييق على العقل، خوفا من فوات كليات الدين أو انفراطها، أو بتعبير الفاروقي: "القلق على مصير الأمة..."، 6 وأن التجربة الغربية آلت إلى التخلص من سلطان الدين - عندما تطرف متثلوه الكنسيونَ في رفض ما أثبته العقل وشهد بصدقه. ويبدو أن هذا الرأي قد وجه المفكرين المسلمين للوعي بمآل كلتا التجربتين، واستثمار هذا الوعي في ابتحاه صياغة أطروحة التكامل المعريف وإسلامية المعرفة، وإن كان بصور متفاوته. وتناقش هذه الدراسة مفهوم التكامل المعرفي وعلاقته بمفهوم إسلامية المعرفة في الأدبيات المتداولة اليوم، وتناقش كذلك أهم التحديات التي واجهت المفهوم، وصور الاستجابات المعرفية لهذه التحديات. وقد أولى الباحث عناية خاصة بالجهود التي جعلت من مفهوم التكامل المعريف عنصرا مهما في محاولات الاستيعاب والتجاوز، لعدد من الأطروحات الفكرية التي نظرت لقضية النهضة والتمدن في البلدان الإسلامية، بمفاهيم وتصورات التجربة الغربية، التي انتهت بأصحابها إلى الدعوة إلى تقليد الغرب، ومحاكاته محاكاة تامة، من منطلق أن ذلك سيقود لمشاركة الغرب في الحضارة خيرها وشرها. وقد اقتضت معالجة موضوع الدراسة، بجانب القراءة التحليلية الناقدة في الأدبيات ذات الصلة بالموضوع، إجراء عدد من المقابلات (المباشرة، وعبر البريد الإلكتروين، والفاكس) مع عدد من الأساتذة والمفكرين المهتمين بقضية التكامل المعرفي وعلى الخصوص الناشطين في مدرسة إسلامية المعرفة.

\section{أولا: النكامل المعرفي: المفهوم والمنطلقات}

ينطلق الداعون إلى إسلامية المعرفة من تقرير مفاده أن الفكر الإسلامي التقليدي، ونظيره الغربي الحديث، يعيشان أزمة، أسهم في تعميقها واستمرارها الخلط المفاهيمي، وغياب الرؤية التوحيدية الكلية. وقد حُددت الأزمة الفكرية بالنسبة للأول في الأدوات المنهجية المستخدمة فيه، وبالنسبة للفكر الغربي في الرؤى الوضعية التي هيمن على كل مجالاته. ويرى منظرو إسلامية المعرفة أن بتحاوز هذه الأزمة بشعبتيها يعد شرطا لتوفير البديل المعريف الإسلامي، وهو ما لا يمكن أن يتم - وفقا لأطروحة إسلامية المعرفة- إلا بعد إعادة

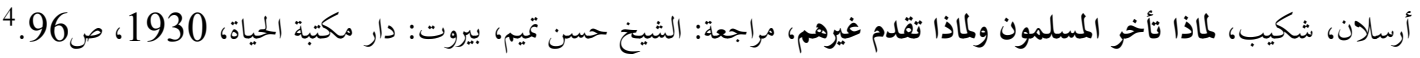

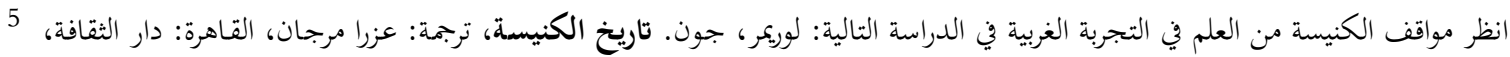
1990، ج5، ص979-29.

الفاروقي، إسماعيل. "الاجتهاد والإجماع كطريف الديناميكية في الإسلام"، مجلة المسلم المعاصر، ع9 (يناير - فبراير - مارس 1977م)، ص5. 6
} 
صياغة فكرية لكلا الفكرين اعتمادا على جهازٍ مفاهيمٍ مغاير يُراعي مبادئ الإسلام ومفاهيمه التأسيسية.

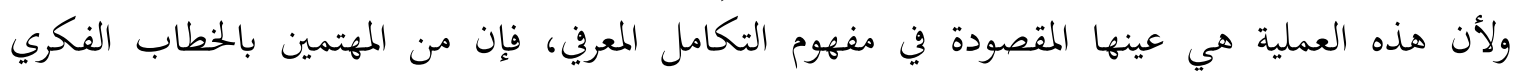

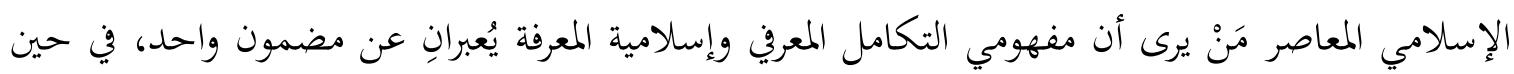

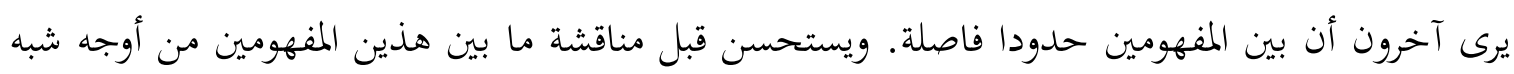

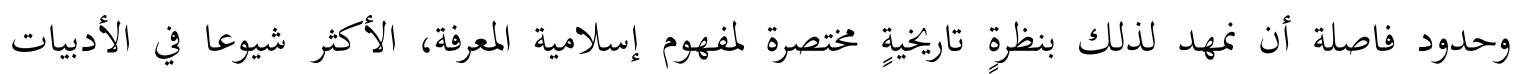

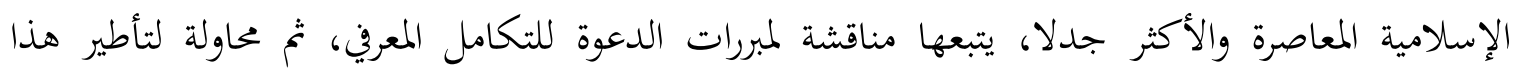

$$
\text { المفهوم بالقدر الذي يميزه عن إسلامية المعرفة. }
$$

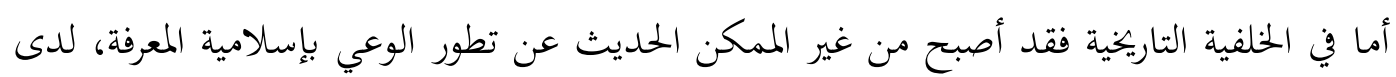

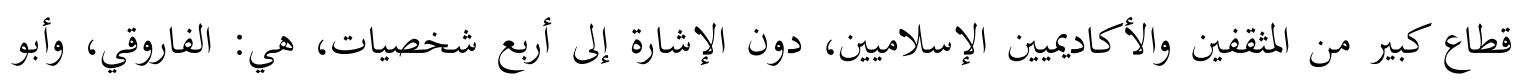

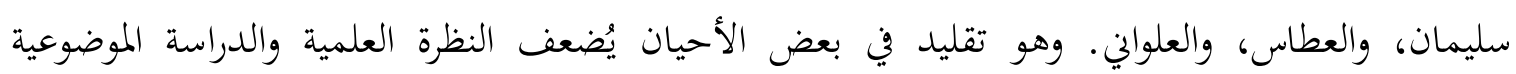

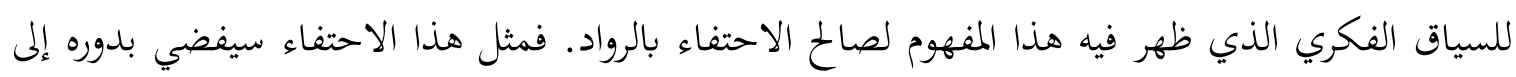

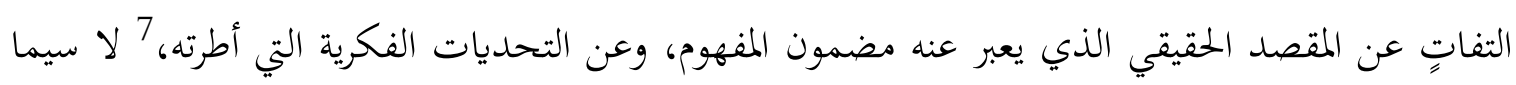

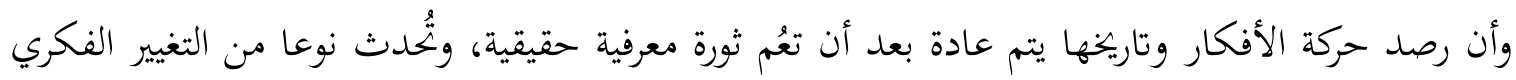

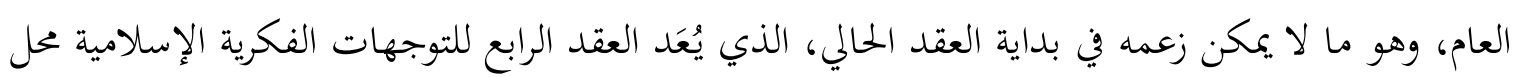

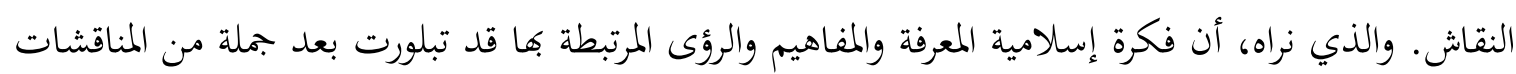

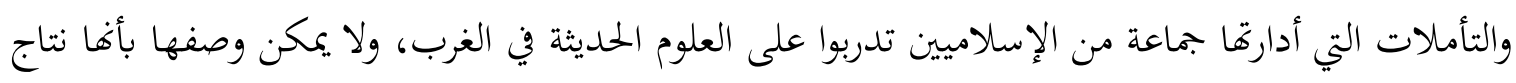
عمل فردي خالص.

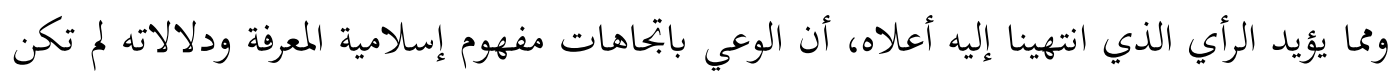

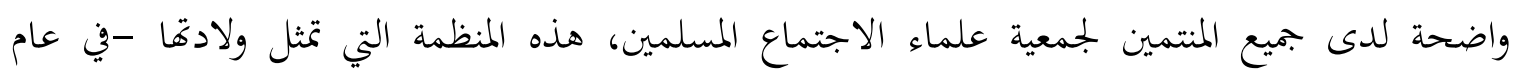

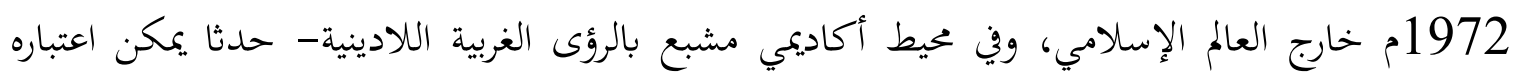

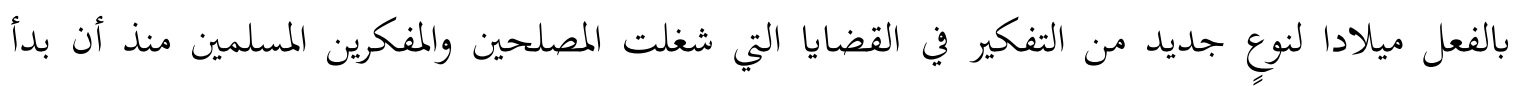

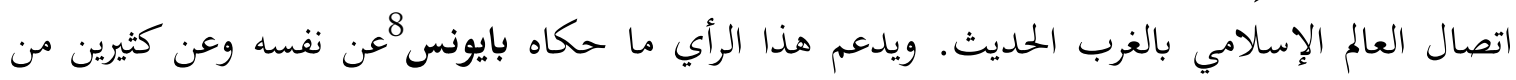

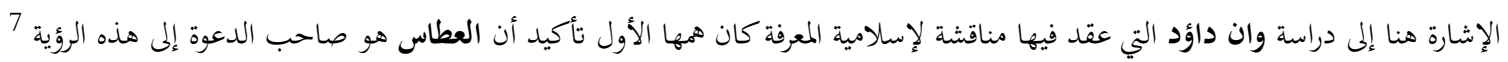

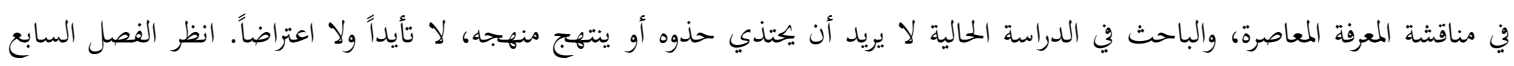

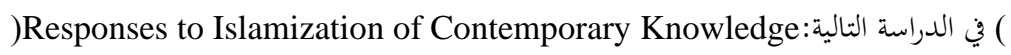

Wan Daud, Wan Mohd Noor, The Educational Philosophy and Practice of Syed Muhammad Naquib Al-Attas: An Exposition of the Original Concept of Islamization, International Institute of Islamic Thought and Civilization, (Kuala Lumpur, 1998), Pp. 371 - 422.

8 Ba- Yunus, Ilyas, Al Faruqi and Beyond: Future Directions in Islamization of Knowledge, The American Journal of Islamic Social Science, Jointly Published by The Association of Muslim Social Scientists and the International Institute of Islamic Thought, Vol. 5, No. 1, 1988, P. 16. 
زملائه أعضاء جمعية علماء الاجتماع المسلمين، الذين لم تكن أهداف هذه المنظمة واضحة عندهم حال تأسيسها.

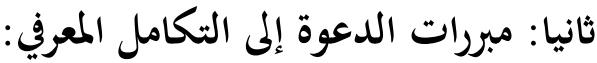

ما يمكن أن نستخلصه من اللمحة التاريخية السابقة هو أن هناك توجهات جديدة في الفكر إلى

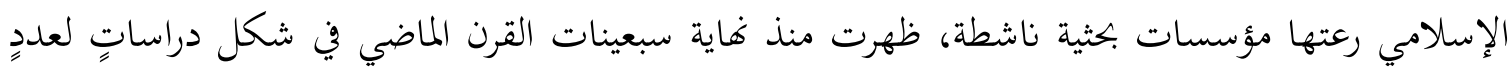

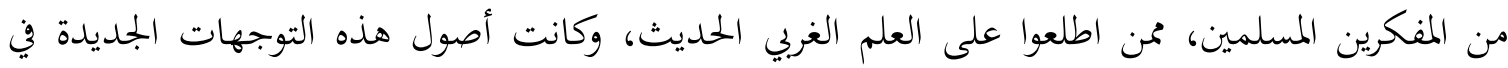
شكل مناقشات وأفكار أولية عامة في غاية الستينات، ثم تبلورت في وقت لاحق لتمثل مشروعا فكريا

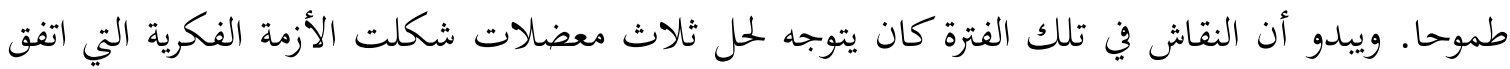

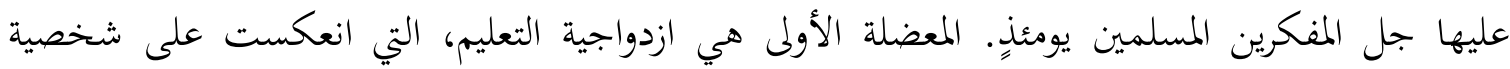

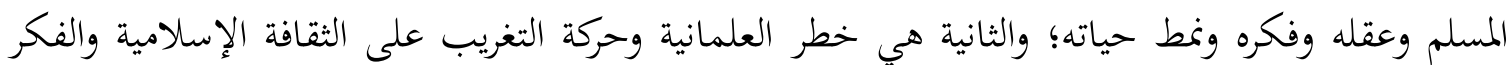

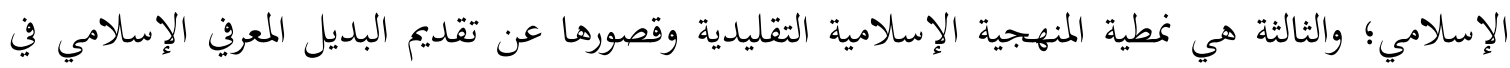

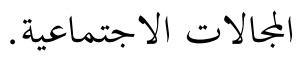

ويمكننا تحليل وعرض هذه المعضلات الثلاث، التي تمثل من وجهة نظرنا مبررات الدعوة لإسلامية

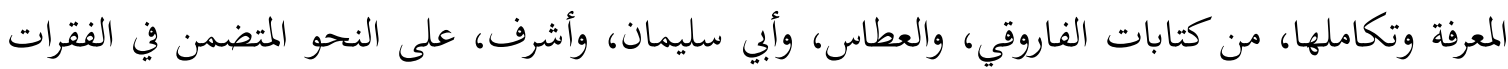

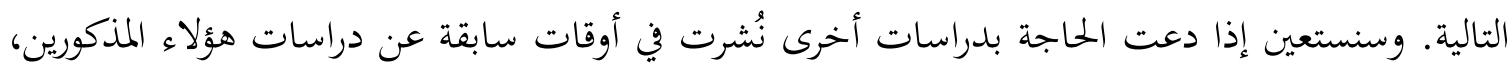

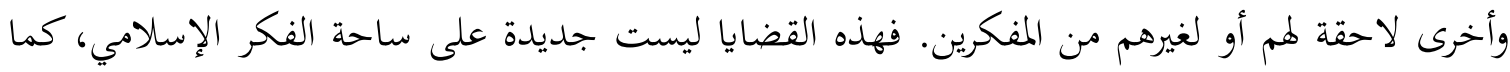

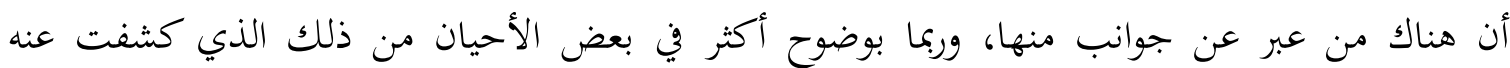

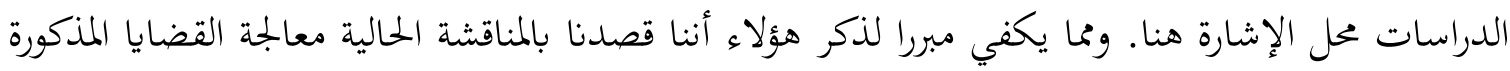
من الزاوية التي نظر بها دعاة إسلامية المعرفة.

1

إن الفكرة التي انبثق عنها المؤتمر العالمي الأول للتعليم الإسلامي عام 1977م حددت المدام مشكلة

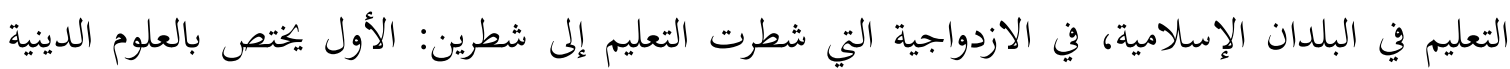

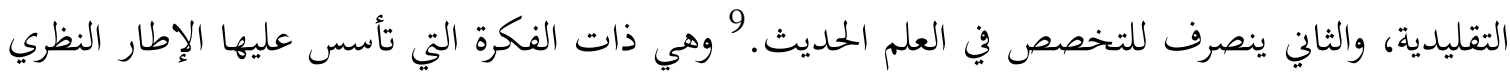
لإسلامية المعرفة عند الفاروقي وزملائه بالمعهد العالمي للفكر الإسلامي.

${ }^{9}$ Ashraf, S. Ali, Islamic Education: An Evaluation of Past Conferences and Post Conference Achievement, 1977-1989, in: Malkawi, Fathi Hasan (Editor), Towards Building A Contemporary Islami Educational Theory, P. 3 - 4. 
المهمة التي تواجه الأمة في القرن الهجري الخامس عشر تتحدد في حل المشكلة التعليمية. إذ يتعذر

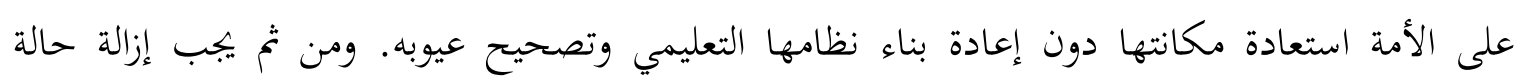

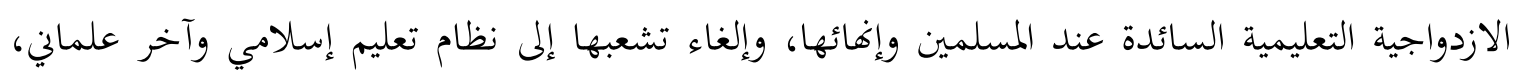
بحيث تحقق اتحاد النظامين وتكاملهما. 10

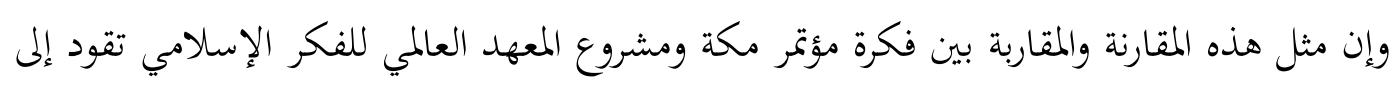

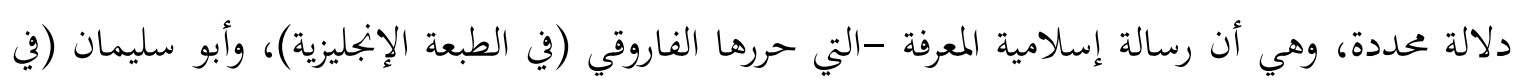

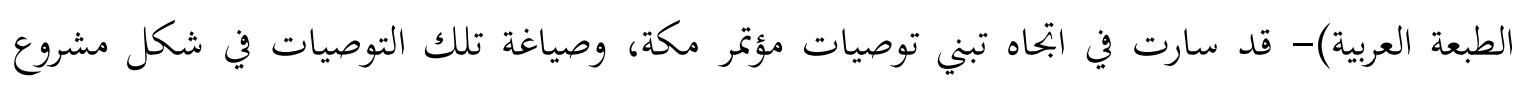

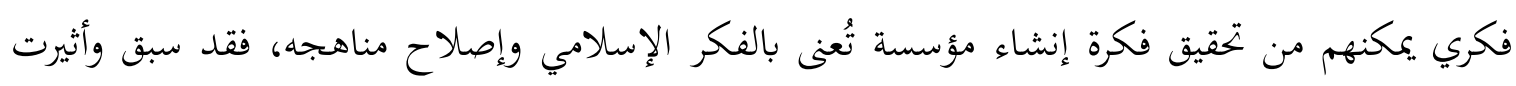

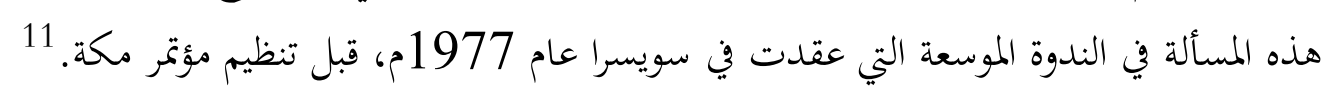

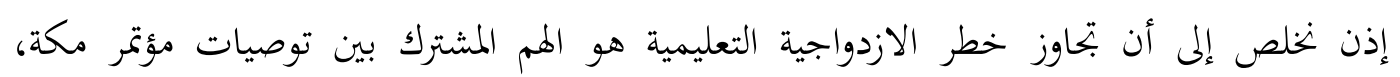

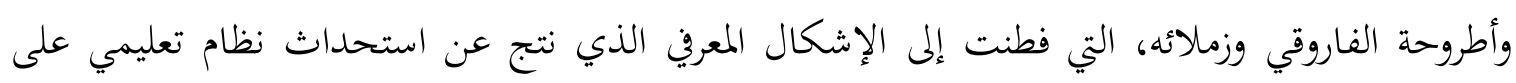

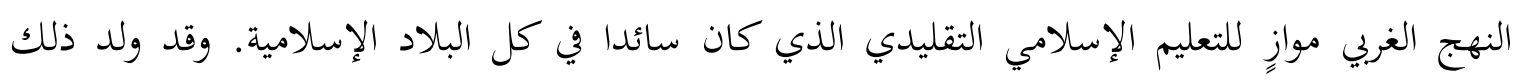
ازدواجية في نظم التعليم منذ عهد محمد علي باشا.

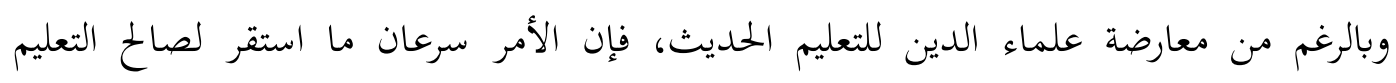

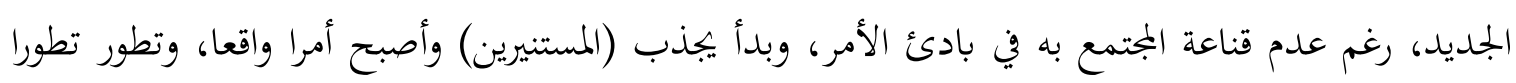

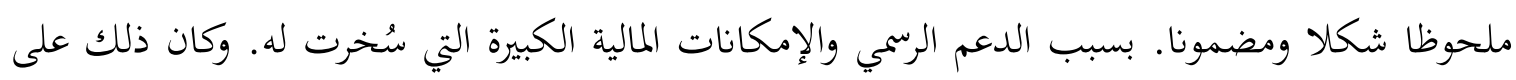
حساب التعليم الديني الذي تأخر بدوره كثيرا. إن هذا التناقض في أوضاع التعليم، 12 كان عاملا مهما للمحاولات التي عرفت في تاريخ الفكر التران

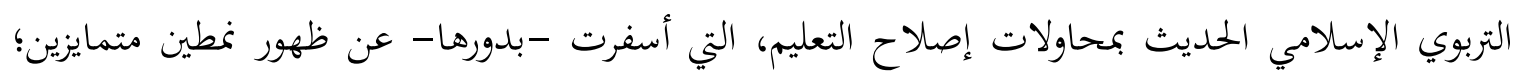

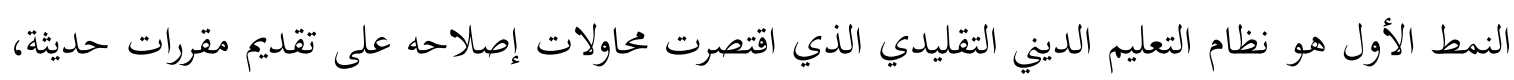

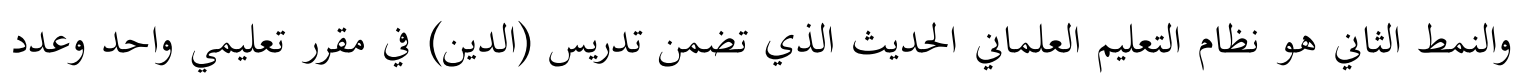
من مقررات (العلوم الحديثة).

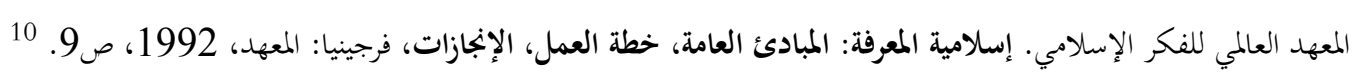

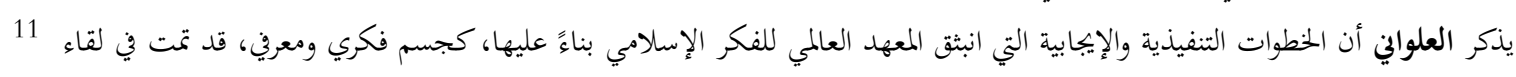

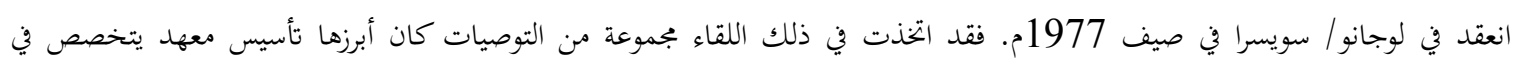

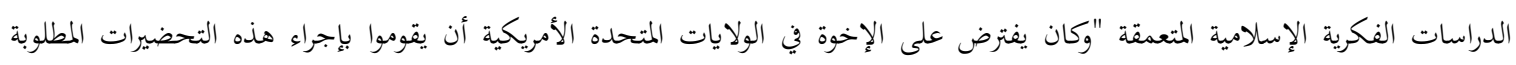

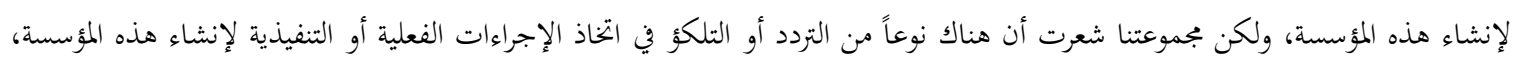

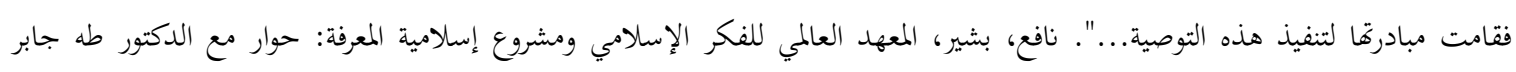

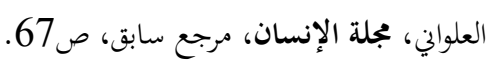

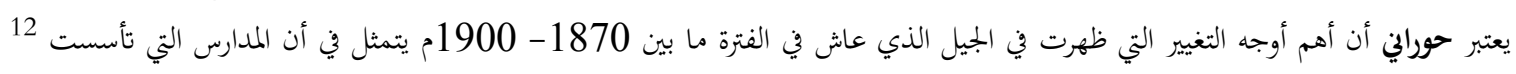

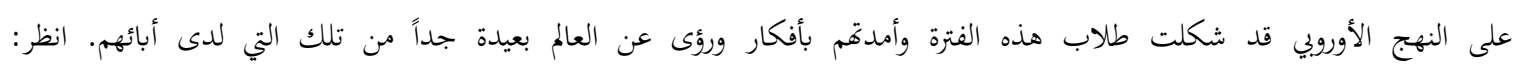
Hourani, Albert: Arabic Thought in the Liberal Age: 1798 -1939, P. vi. 
بيد أن تحديث نظام التعليم الديني التقليدي قد تم دون تحويلٍ لمناهج (العلوم الحديثة) عن أساسها المفاهيمي العلماني الذي بنُيت عليه، فأُدرجت من غير أي تعديل أو محاولة "لأسلمتها" وإعادة إنتاجها من منظور إسلامي، يسمح لما أن تتكيف مع الإطار الفلسفي للنظام المراد انضمامها إليه. وسبب ذلك أن القائمين على هذه المحاولات لم يكترثوا إلى أن النظرة الوجودية العلمانية، التي تأسست عليها مقررات التعليم الحديث، تعارض الأساس الفلسفي الذي يقوم عليه نظام التعليم الديني. وفي هذا السياق قصد بالدعوة لمشروع التكامل المعرفي رفض المحاولتين السابقتين، لتجاوز تلك الازدواجية. 13 ففكرة التكامل المعريف تاريخيا جاءت لاحقة لما عرف، من جهة، بمحاولات إصلاح التعليم الديني وتحديثة من خلال تدريس المواد الاجتماعية الحديثة، ذات المضامين العلمانية من غير أي تحويل فلسفي لما ضمن المنهج المتبع في النظام التقليدي؛ ومن جهة ثانية، بعد محاولات أخرى تقوم على فكرة ساذجة ظن أصحابها أن إضفاء الصبغة الإسلامية على نظام التعليم الوافد من الغرب ممكن، وذلك بمجرد إدخال مقررات عن الدراسات الإسلامية، وإلزام الطلاب بها في كل مراحل التعليم.14 وهو الإشكال الذي اعتبرته رسالة إسلامية المعرفة جوهر الأزمة الفكرية للأمة الإسلامية، ووضعت خطة لحله والإسهام في تجاوزه. 15

\section{2. خطر العلمانية وحركة التغريب على الثقافة الإسلامية والفكر الإسلامي:}

ومن المقدمات الأساسية في أطروحة العطاس في إسلامية المعرفة اعتبار أن قيام حركة الحداثة في النصف الثاني من القرن التاسع عشر "بداية فعلية للتقويض الواسع المنظم لتراثنا المعريف، وقيادته الفكرية والروحية، مما جعلنا اليوم نجني من هذه الحركة الخطيرة تراثا ضخما من التشويش الفكري والثقافي والروحي". 16وهذا التقويض الواسع للتراث المعريف الإسلامي يعبر عنه العطاس بمصطلح "تغريب المعرفة Westernization of Knowledge المعرفي الإسلامي، وبناء الرؤية الإسلامية للوجود في حقل العلوم الإنسانية الحديثة. ويستخدم العطاس مفهوم "إسلامية المعرفة" بحيث يعني: "نقض المعرفة الغربية Dewesternization of Knowledge". 17 وبناء على إلى

حول هذا المعنى انظر تصدير سيد علي أشرف للكتاب التالى: 13

Hashim, Rosnani: Educational Dualism in Malaysia: Implications for Theory and Practice, P. v.

في باكستان، على سبيل المثال، أوصى التربويون المسلمون وزير التعليم الأسبق فضل الرحمن، حينما استشارهم حول كيفية إسلامية نظام 14

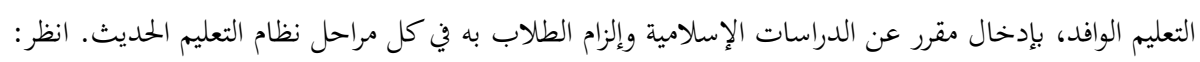

Ashraf, S. Ali, Islamic Education: An Evaluation of Past Conferences and Post Conference Achievement: 1977 - 1989, P. 3 - 4.

المعهد العلمي للفكر الإسلامي، إسلامية المعرفة المبادئ وخطة العمل والإنجازات، مرجع سابق، ص9. 15

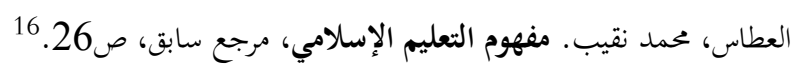

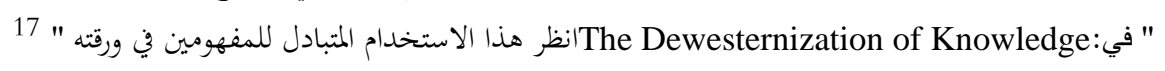

Webb, M. Jennifer, Powerful Ideas: Perspectives on the Good Society, (The Granlana Programme, Australia, 2002), Vol. 2, Pp. 231 - 240. 
ذلك فإن نقد العطاس للعلمانية قد ابته نحو مناقشة الأصول الفلسفية للتحولات الثقافية والفكرية التي شهدها الغرب في العصر الحديث.

وينبه العطاس للتمييز -الذي يقره الفكر الغربي- بين العلمنة والعلمانية، فالعلمنة "مسارا لا فاية له

ولا حدود، وتخضع فيه القِيَم والرؤى الكلية للمراجعة الدائمة حسب ما يقتضيه التغيير في المسيرة (التطورية)

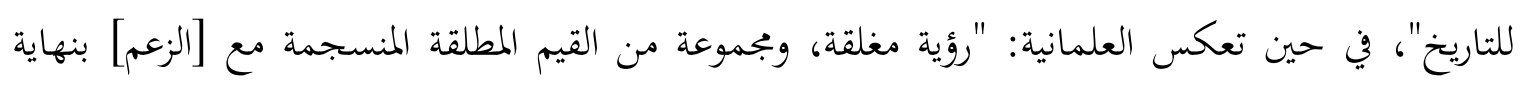
للتاريخ تنطوي على أهمية كبرى للإنسان". 18

واضحٌ إذن أن دراسة العطاس محل الإشارة لا هتم بالقضايا المألوفة في الأدبيات السجالية في دئي موضوع العلمانية والإسلام، فالرؤية التي ينظر بها العطاس لإشكالية سحب النسبية التاريخية إلى المجتمعات المسلمة قائمة على الوعي بخطورة المقولات الأساسية لمفهوم النسبية التاريخية، المتمثلة في: "ضرورة بتريد الطبيعة من المعاني والإحالات الدينية الزائدة، وترير السياسة من الدين، ونزع القداسة عن القيم". وخطورة هذه القضايا تتمثل في نقاط ثلاث: أوها: أن الفكر الديني في التجربة المسيحية الغربية عندما فشل في احتواء تيار العلمنة تقبل فكرة المصالحة معها، وهي فكرة "تنطوي على عملية هدم للذات". 19 وثانيها: أن الإنسان الغربي "يميل دائما إلى النظر إلى ثقافته وحضارته على أها طليعة الحضارات والثقافات الإنسانية، وإلى تجربته الخناصة ومستوى وعيه بحسباهما مثثلين (لأرقى) ما بلغه الجنس البشري". وثالثها: أن روح البحث العلمي في ثقافة الغرب وحضارته قد نشأت مترافقة مع خيبة أمل في الدين كما فهم في تلك الحضارة. ولكن، (وهنا وجه الاعتراض)، هل تماثل المزاعم الخاصة بالعلمنة أوضاع الإسلام؟ وهل يؤثر مسار العلمنة في العالم الإسلامي في المعتقدات الإسلامية بالطريقة التي أثر بها في معتقدات الإنسان الغربي، لا سيما وأن العلمانية اليوم لها وجود في المجتمعات الإسلامية؟ يوافق أمزيان العطاس فيما خلص إليه، ويشاركه الرأي في أن العلمنة ظاهرة غربية، حيث يرى أمزيان أن التقاليد التي سار عليها التفكير الديني المنهار في التجربة الغربية جعلت الاتحاه العلمي في الغرب "يضع العلم المرتبط بالحياة وبكل ما هو واقعي بمثابة النقيض للدين... وتلك هي المأساة التي انحدرت إليها العلمانية الناشئة والاتحاه الوضعي على السواء". 20 وعلى الرغم من أن هذا الوضع لم يواجهه العلم في العالم الإسلامي الذي "أصل اجتماعيته جنبا لجنب مع روحانيته"، 21 إلا أن هناك تيارا كَونَهُ عدد من المثقفين في العالم الإسلامي اعتقد بصحة المقولات المعرفية الغربية، وبدأ يتبنى فكرة مماثلة البنية الفكرية الغربية لنظيرتا الإسلامية، دون إدراك لخصوصية السياق الفكري الإسلامي. ولكن

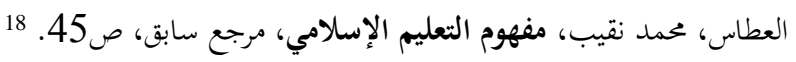

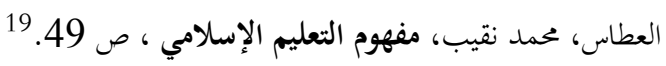

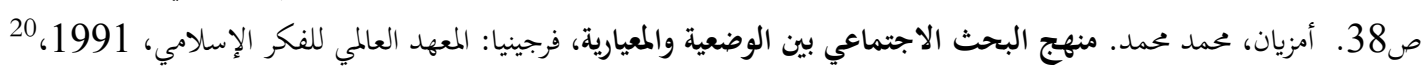

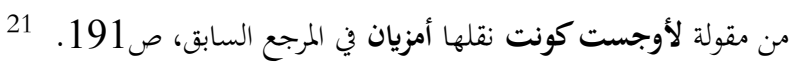


المحاولات التي قام بها أصحاب هذا التيار باءت بالفشل في فهم واقع المجتمع الإسلامي، فظهرت دعوة العودة إلى الذات، وبتحاوز مرحلة التقليد. 22 تمثل بعضها في محاولة تحديد الأسس الإسلامية للعلم.

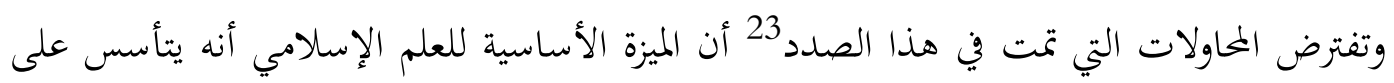
الوحي، فالعلم الذي ينطلق من تصور كلي مستمد من مصدر متعالٍ على الذات (القرآن والسنة) علم يسعى للتحرر من النزعات الذاتية والتوجهات الإيدلوجية، وهذه قضية في غاية الأهمية، وقد أهدرت في العلوم الإنسانية الحديثة المتحيزة بالضرورة. وتفترض هذه الرؤية كذلك أن مبدأ التوحيد بالنسبة للمسلم ضابط منهجي له قيمته في ضمان التحرر من تلك النزعات، وأنه يخرج العلم من دائرة العقل التي سجن فيها باسم الحياد الأخلاقي، وأفقدته دلالته ووظيفته.

\section{3. نمطية المنهجية الإسلامية التقليدية وقصورها عن تقديم البديل المعرفي الإسلامي:}

وإذا آلت العلوم الحلديثة وانتهت بمحاصرة الدين والثقافة الدينية، فإن الملتزمين برؤى النظام التقليدي، في الطرف الآخر، لم يتوافر عندهم الوعي الكافي بالتعقيدات الفكرية الحديثة. وهذا الوضع تطلب البحث عن فئة ثالثة تكون ملمة بقيم المجتمع وتقاليده وقادرة في ذات الوقت على الإلمام بالحكمة التي يُمكن

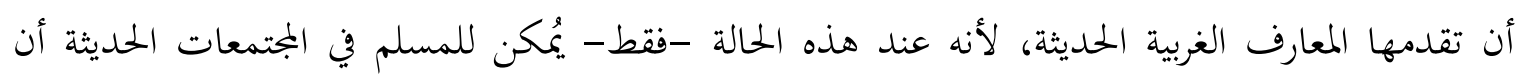
تتكامل عنده مبادئ الأخلاق والسلوك الروحي مع المعرفة العقلية المعاصرة. 24وهذا التحديد لمهمة إيجاد فئة ثالثة ملمة بقيم المجتمع وتقاليده، وقادرة في ذات الوقت على الإلمام بتلك الحكمة، يعني أن بتحاوز إشكال الازدواجية والثنائية التعليمية، وهو إشكال يتضمن جملة من التحديات الاجتماعية والثقافية والفكرية يمكن أن يُنظر لها -إضافة إلى النظر فيها من زاوية خطر المعرفة الحديثة على الفكر الإسلامي- من زاوية إخفاق المعرفة الإسلامية التقليدية في تقديم البديل المعرفي الأكثر أصالة وإحاطة بالتصورات الإسلامية في مواجهة التحديات الفكرية الحلديثة.

ومن الملاحظ أن مؤتمر مكة ومؤتمرات المتابعة لم تتجه ناحية نقد العلوم الإسلامية التقليدية ومؤسسات التعليم الديني، أو تزعم أن هذه العلوم هي الأخرى تعكس أزمة العقل المسلم، وأن إصلاحها شرط لنهضة الأمة ولاستعادة ريادتا في مجالات الاستخلاف والعمران. بل اقتصر المؤتمر على مناقشة خطر العلمانية والقيم التي تحملها العلوم الغربية الحديثة على العقل المسلم. وقد أشار أشرف إلى أن استدراك هذه

انظر مناقشة أمزيان للمفاهيم الوضعية التي تبناها بعض المفكرين العرب في المرجع السابق، ص211، 222

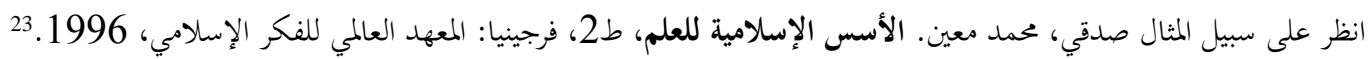
${ }^{24}$ Hassan, M. Kamal: Intellectual Discourse at the End of the $2^{\text {nd }}$ Millennium: Concerns of A MuslimMalay CEO, P. 59 - 60 
القضية قد نبه إليه أبو سليمان في دراسته للعلاقات الدولية في الإسلام، التي قادته للوقوف عند قصور المنهجية التقليدية.

ولقد واصل أبو سليمان تطوير رؤيته في نقد المنهجية التقليدية وتقويمها في عدد من البحوث والدراسات، وتوجه نقده إلى منهج أصول الفقه الذي يعتبره أساس المنهجية الإسلامية التقليدية، كما أثار قضايا تتعلق بجذور ما عرف في التاريخ الإسلامي بأدبيات العقل والنقل، وناقش خطورة التسامح في القول بالنسخ بالقدر الذي يجعل من مجتمع المدينة نموذجا ينبغي أن ينشده التشريع الإسلامي، وتحدث عن أهمية مراعاة الأبعاد الزمانية لنصوص السنة النبوية، والأعمال التراثية الإسلامية، بحيث يتم استيعاها على وجٍِ 26

صحيح. وثمة ملاحظتان مبدئيتان في قضية المنهجية الإسلامية: أولاهما: أن البحث عن منهج يتبين به المرء الجانب الإسلامي الخالص في دائرة العلوم والمعارف المكونة لميراث الأمة الإسلامية، يتطلب البحث في نواحي الفكر الإسلامي المختلفة: في الفلسفة، والتصوف، وعلم التوحيد والكلام، وعلم أصول الفقه. 27 وإذا كان الأمر كذلك، فإن أبا سليمان في دراسته لقضية المنهجية الإسلامية، اكتفى فقط بنقد منهج علم أصول الفقه، دون تتبع قضية المنهجية الإسلامية في جوانب الفكر الإسلامي المختلفة، ولكنه أولى عناية كبيرة بقضية القياس وهو يناقش منهج أصول الفقه. وقد يكون مبرر ذلك أن منهجه في دراسة العلاقات الدولية قد بناه على منهجية استخلاص الأحكام. ولا يخفى أن اعتماد مثل هذا المنهج في دراسة مستجدات قضايا السياسة والعلاقات الدولية يتطلب من الباحث أن يجري عددا من التدخلات في الإسهامات الإسلامية المبكرة. وقد انتهت المداخلات التي عقدها أبو سليمان إلى الربط بين الأصول التي وضعها علماء الشريعة الإسلامية ووأد العلوم الاجتماعية في التاريخ الإسلامي، فمنهجية التشريع الإسلامي التقليدية يحتل القياس فيها مرتبة متقدمة، بعد القرآن والسنة والإجماع، في حين أن أصولا مثل الاستحسان والمصلحة تحتل مرتبة متأخرة في سلم تلك الأصول. "وهذه الأصول التي تعتبر ثانوية عندهم هي أصول مهمة للغاية لتأسيس علوم اجتماع إسلامية، فهذه الأخيرة لا بتحي فيها كثيرا تلك القواعد الأصولية الأصلية". 28

يقول أشرف عن تنبيه أبو سليمان لهذه القضية ما نصه:25

'Abdul Hamid Abu Sulayman, who attended the first world conference raised this issue, though not at that conference but in recent work, and attacked the traditional method of interpreting the Qur'an and Sunnah'. See: Ashraf, S. Ali, Islamic Education: An Evaluation of Past Conferences and Post Conference Achievement: 1977-1989, P. 38.

وقد توقف أشرف في مسالة قبول أو رفض ما أثاره أبو سليمان عن المنهجية التقليدية فوصفها في المرجع السابق نفسه بأها:

'This is a major sphere for new investigation because Abdul Hamid Abu Sulayman's view cannot be accepted or rejected so easily'.

أبو سليمان، عبد الحميد. أزمة العقل المسلم، الرياض: الدار العالمية للكتاب الإسلامية، 1994، ص13-103. 26

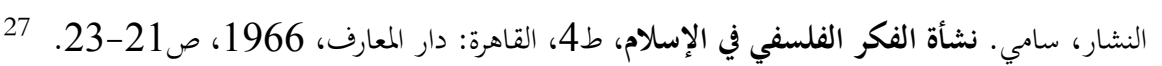

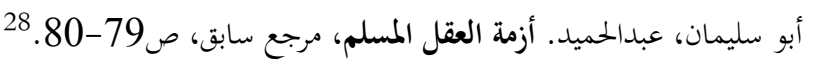


وثانيهما: إن افتراض أن علم أصول الفقه قد تطور منذ وقت مبكر في التاريخ الإسلامي، في ظل انفصام القيادة العلمية والسياسية يعني -ضمن ما يعني- محاولة قراءة علم الأصول بمنطق تشكله الداخلي، في معزل عن الظروف الخارجية: السياسية والاجتماعية، لكن ذلك لا يعني بالضرورة نفي وجود أي نوع من العلاقة بين الظروف السياسية التي شهدها التاريخ الإسلامي، وتَشَكل علم الأصول وتطوره. فقد لاحظ عبدالمجيد الصغير أن: مراعاة العلاقة الجدلية بين المعريف والمجتمعي، أمرٌ في غاية الأهمية لإبراز العلاقة الجدلية المتبادلة بين علم الأصول والظروف السياسية العامة. 29 فبالنسبة للصغير تتمثل أهمية بيان الجانب السياسي في علم أصول الفقه، في قيمته العلمية لفهم حركة العلم في السياق العربي الإسلامي بصورة أقرب وأدق من الصورة التي تزدحم بها كتب الطبقات والسير لأعلام أصول الفقه، التي تركز كثيرا على التجريد، وتعرض الته القضايا وكأنما كتبت في فراغ سياسي؛ وكأنما علماء الأصول كانوا منعزلين عن قضايا السلطة والشرعية والطاعة والحراك الاجتماعي والسياسي في عصرهم. 30 من جهة أخرى لاحظ أبو سليمان في كتابه "أزمة العقل المسلم" أن المنهجية التاريخية في التشريع الإسلامي غلب عليها الاهتمام بقضايا الفرد الفذ، بحيث احتلت فيها القضايا العامة التي يتوجه إليها اهتمام العلوم الاجتماعية والإنسانية مرتبة ثانوية. وهي ملاحظة أشار إليها عدد من العلماء. منهم على سبيل المثال: ابن عاشور، الذي يرتبط عنده البحث في مقاصد الشريعة بالبحث في نظام الاجتماع الإسلامي

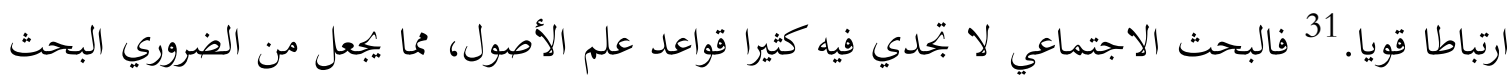

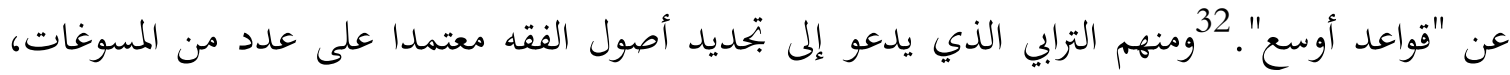
أهمها: أن "الفقهاء ما كانوا يعالجون كثيرا قضايا الحياة العامة". 33 ومن خلال تحليله لبنية علم الأصول وتطوره التاريخي، في ضوء التحولات العامة التي كانت تحصل في الاجتماع الإسلامي في قرونه الأولى، يخلص الترابي إلى أن كثيرا من قواعد علم الأصول وأبوابه -التي كان يمكن أن تتطور وتتسع لاستيعاب قضايا الحياة العامة- قد أصابها الانحسار، وما انفك بعضها "تحاصره المجادلات الفقهية حتى أردته في مهلده". 34ولأن "ما عطل من الدين أكثره يتصل بالقضايا العامة والواجبات الكفائية"، فإن الترابي يؤكد الحاجة "للتواضع على منهج أصولي ونظام يضبط تفكيرنا الإسلامي حتى لا تختلط علينا الأمور، وترتبك المذاهب، ويكثر سوء

الصغير، عبد الجيد. الفكر الأصولي وإشكالية السلطة العلمية في الإسلام: قراءة في نشأة علم الأصول ومقاصد الشريعة، بيروت: دار 29

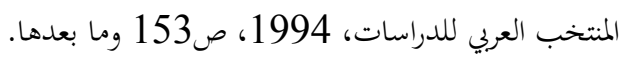

في تقويم أطروحة الصغير انظر مراجعة إبراهيم محمد زين لكتاب الصغير السابق في: مجلة إسلامية المعرفة، س1، علعات، 1995م، 190 ص 1550

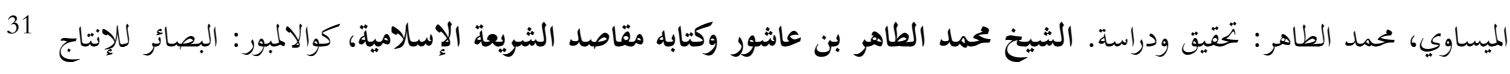

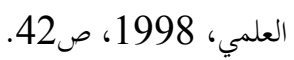

المرجع السابق، ص42.

الترابي، حسن عبد الله. قضايا التجديد: نحو منهج أصولي، الخرطوم: معهد البحوث والدراسات الاجتماعية، 1990، ص196. 33

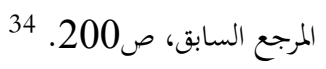


التفاهم، والاختلاف في مسائل تتصل بالحياة العامة: السياسية، والاجتماعية، والاقتصادية، والدولية وغيرها، مما يؤثر في وحدة المجتمع المسلم وغضته". 35 ومثل هذا النظر في بتاوز المنحى التجزيئي في تفهم أحكام الشريعة، لتأسيس رؤية كلية تصلح للإسهام في حل القضايا العامة في الاجتماع الإسلامي، قد وجد كذلك، كما أوضح الميساوي، 36 عند الصدر وعدد من علماء الشيعة. ولسنا هنا بصدد التأريخ لمذه المسألة، إذ يكفي أن نتبين أها قد تواردت عند عدد من علماء الأمة ومفكريها في العصر الحديث. ويتضح كذلك من النظر المتأني في ملف المنهجية الإسلامية لمشروع المعهد العالمي للفكر الإسلامي، أن القضية الأساسية المثارة لا تتصل بتجاوز عطاء المنهجية التقليدية أو التراث الفقهي بهذا المعنى الهدمي، ولكنها دعوى لربط العلوم الاجتماعية، وبمستوى أقل العلوم الطبيعية، بالرؤية الإسلامية الكلية، وهو هدف بعيد المنال إذا أنيط تحقيقه بمنهجية التشريع التقليدية التي يمثلها منهج أصول الفقه.

ثالثا: المبادئ العامة لمفهوم التكامل المعرفي: في دراسته "العلم والحضارة في الإسلام" لاحظ نصر، 37 أن التصور السائد عن العلم في العصر العصر الحديث، قائم على النظر إلى تاريخ العلم على أنه تراكم تقني آخذ في النمو، وتطوير وتذذيب المناهج الكمية في دراسة الطبيعة. وأن هذا التصور الذي شكلته الرؤى الغربية أصبح هو المعتمد في تقويم علوم الحضارات الأخرى، بحيث يتم تقويمها في ضوء مفاهيم العلم الحديث. ويعترض نصر على إعمال هذا المبدأ في دراسة العلم والحضارة في الإسلام، بحجة أن التاريخ بالنسبة للمسلم هو سلسلة من الحوادث تأتي متأثرة بمبادئ الإسلام التي لا يعتريها الزوال، وأن المسلم يهتم في المقام الأول بمعرفة تلك المبادئ والعمل على تحقيقها. ويخلص من تأكيده هذا المبدأ في دراسة الحضارة الإسلامية إلى أن الإسلام عندما انتشر واتصل بميراث الحضارات السابقة، انصرف اهتمام الحضارة الإسلامية آنذاك عن الانشغال بتغيير موروث تلك الحضارات وتكييفها أو البحث عن أصالتها في الإسلام. بل كان كل هَم العالم المسلم أن يحقق مبادئ التوحيد، لأن العلوم والآداب تقوم في الإسلام على فكرة الوحدة الربانية 'The Divine Unity، التي تنتهي إليها مظاهر التعدد والكثرة في الكون المخلوق. "ففي ضوء هذه الفكرة أصبحت الآداب والعلوم في ظل الحضارة الإسلامية تبحث عن امتلاك الاستقرار وبلورة الموروث الجلديد اعتمادا على مبادئ الإسلام الخالدة، التي منها صدرت العلوم والآداب الإسلامية وتصاعدت". وهذا يعنى -بمنطق الحجج التي ساقها نصر- أن فهم جوهر العلوم الإسلامية يقتضي فهم بعض مبادئ الإسلام نفسه. 38

\footnotetext{
المرجع السابق، ص203-204.

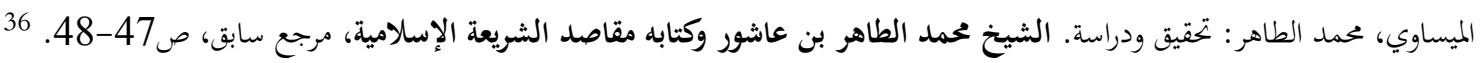

${ }^{37}$ Nasr, Seyyed Hossein: Science and Civilization in Islam, P. 21.

${ }^{38}$ Ibid., p. 21-29
} 
إن التنبيه السابق الذي جاء على ذكره حسين نصر، في ثنايا مقدمة دراسته آنفة الذكر، التي نُشرت للمرة الأولى عام 1968م، من الأهمية بمكان لفهم التوجهات الجديدة في مبحث التوحيد، التي عبر عنها عدد من المفكرين في العصر الحديث، ولفهم المناقشات الفكرية الإسلامية المعاصرة لموضوعات المعرفة من خلال علاقتها بمبادئ الإسلام العقدية. لا سيما وأن هذه التوجهات قد ساعدت العقل المسلم كثيرا في العصر الحديث على التخلص من قضايا علم الكلام القديم، والجدل المذهبي، ومهدت له السبيل لفهم دوره الرسالي في التحقق بمبادئ الإسلام في كل جوانب الفكر والحياة، التي هو جزء منها. فعلم الكلام القديم، بنزوعه إلى التجريد القوي، وباعتماده على الطابع الجلدي العقلي والمنطقي الخالص، وبانتهائه إلى الخوض في مسائل عارضة جزئية، طبيعية حسية أو مفارقة للحس، قد انتهى إلى أن يكون علما جافا لا حياة فيه، أو على الأقل كف عن أن يكون له أي تأثير في حياة الإنسان المسلم المشخصة. 39 لقد ظهرت التوجهات المشار إليها في عدد من المؤلفات الحديثة، لتحقيق أغراض متباينة: 40 منها ما يتصل مباشرة بالإشكال المعرفي، 41 ومنها ما هو حركي - يتصل بقضية تفعيل مبادئ الإيمان في كافة شؤون الإنسان، بحيث يتحقق بها المسلم المعاصر وتحرك فاعليته، ويكون لها أثر واضح في حياته. 42 وفي الخطوة التالية يتوجه الاهتمام لعرض دراسة للفاروقي تمثل أدبيات النوع الأول: المتصلة بالإشكال المعرفي، لمناسبتها للموضوع محل الدراسة الحالية. تُعَد دراسة الفاروقي "التوحيد: تطبيقاته في الفكر والحياة"43 جهدا فكريا معاصرا لفهم مبادئ الإسلام من خلال عدد مختلف من زوايا النظر، حاول مؤلفها أن يجيب عن جدوى معرفة التوحيد، الذي هو جوهر الحضارة الإسلامية، في ظل الظروف والتحديات المعاصرة. وقد صمم الفاروقي دراسته بحيث تستجيب لتغطية موضوعات في الأديان المقارنة، والمعرفة، والتاريخ، والفلسفة، والأخلاق، والاجتماع.

جدعان، فهمي. أسس التقدم عند مفكري الإسلام، مرجع سابق، ص192. 39

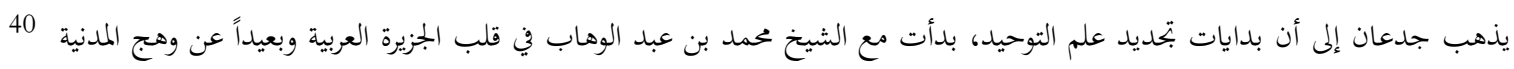

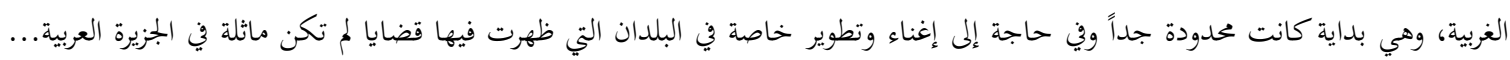

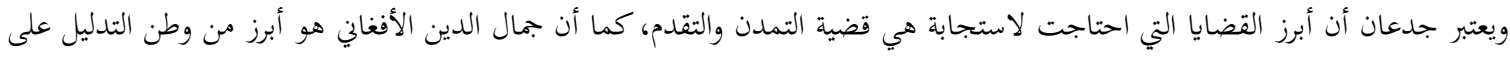

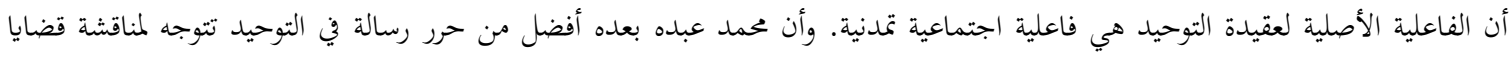

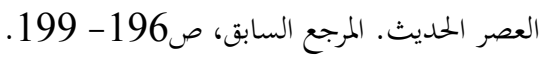

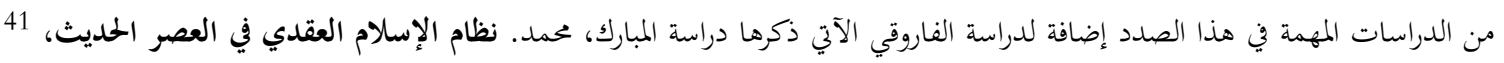

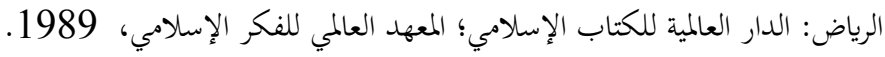

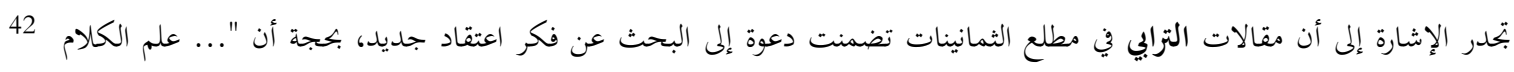

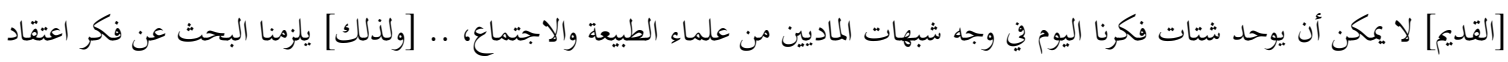

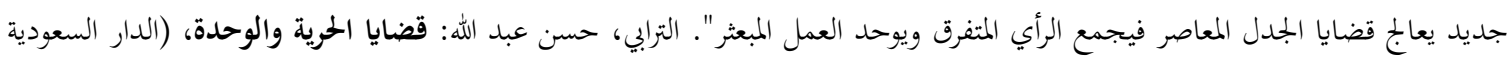

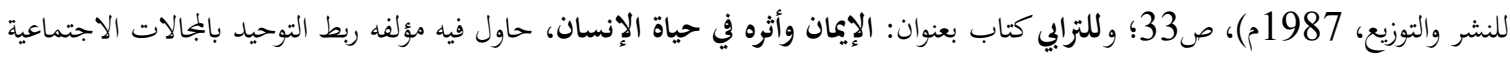
والاقتصادية والسياسية العامة.

${ }^{43}$ Al- Faruqi, Ismail Raji, Al-Tawhid: Its Implications for Thought and Life. 
إن التوحيد - في دراسة الفاروقي هذه- إضافة إلى أنه بتحبة دينية، يشغل فيها الخالق وضعا مركزيا، حيث يستحوذ الإيمان على كافة أفعال الإنسان وأفكاره، فإنه كذلك تصور عام 'worldview، للحقيقة، بما فيها الدنيا كلها والحياة كلها والتاريخ كله. فالتوحيد يعكس المبادئ الآتية: 1- الثنائية ’Duality‘ وهذا المبدأ يؤكد التمايز في حقيقة الخالق والمخلوق، فالله جل جلاله؛ هو الخالق الوحيد، المنزه الصمد. أما عالم الخلق فهو الزمان والمكان بكل ما فيهما من موجودات وحوادث. وهذه الثنائية للحقيقة هائية وقطعية. فلا يمكن للخالق أن يتحد أو يتصل وجوديا أو يحل أو يتجسد في المخلوق، ولا المخلوق أن يتحد أو يتصل وجوديا في الخالق أو يسمو بنفسه إلى مرتبة الخالق. 2- الإدراكية ’Ideationality‘) وهذا المبدأ يبين أن العلاقة بين عالمي: الخالق والمخلوق، أي عالمي الحقيقة، علاقة إدراكية في طبيعتها. فلا صلة بين الخالق والإنسان المخلوق إلا بقوة العقل، وهي قوة فطرية تؤهل المخلوق لإدراك إرادة الخالق: سواء عن طريق تدبر الوحي، أو عن طريق التعقل والنظر في المخلوقات لاكتشاف سننها وقوانينها. 3- الغائية ’Teleology' أي أن لعالم الخلق غاية من وجوده، وهي تهقيق إرادة الخالق. فالله سبحانه وتعالى لم يخلق الكون عبثا ولا باطلا، بل أحسن خلق كل شيء وقدره تقديرا. وإرادة الله في خلقه ما عدا الإنسان تتحقق بالضرورة، وذلك بأن الله وضع تلك الإرادة سنة أو فطرة في جبلة المخلوق. أما في الإنسان فإرادة الله تتحقق باختياره فضلا عن تحققها بالضرورة في جبلته. ولإرادة الإلهية التي تتحقق باختيار الإنسان مرتبة أعلى من مرتبة الإرادة المتحققة بالضرورة. 4- القدرة الإنسانية 'Capacity of Man'، يترتب على المبدأ السابق -القائل أن الخلق كله هُلق لغاية- أن الإنسان لديه القدرة على تحقيق تلك الغاية. ففي الإنسان قوة على تغيير نفسه، وتغيير مجتمعه وتغيير الطبيعة المحيطة به، وفي نفس الإنسان ومجتمعه ومحيطه الطبيعي قوة على تقبل فعل الإنسان. 5- المسؤولية والجزاء 'Responsibility and Judgment' لأنه إذا كان الإنسان مكلفا بتحقيق أوامر الخالق، وقادرا على القيام بذلك التكليف، فإنه يصبح مسؤولا؛ إذ بدون المسؤولية والحساب تسقط جدية التكليف. فالحساب قائم في التاريخ وبعده. يؤتى المستجيب للأمر، المحقق له، فلاحا وسعادة ويُسرا، ويؤتى العاصي للأمر عذابا وإخفاقا وضيقا. 44 على ضوء المبادئ السابقة يخلص الفاروقي إلى أن التوحيد يعني أولا: رفض ما يخالف الحقيقة؛ وثانيا: رفض استمرار التناقض؛ وثالثا: الانفتاح، وتقبل الدليل المخالف.45 وتتمثل أهمية مبادئ التوحيد السابقة في المجال المعرفي -عند الداعين لإسلامية المعرفة- في ضرورة صياغة مبادئ المعرفة على ضوء مبادئ وجودية خمسة حددتا رسالة إسلامية المعرفة في: وحدة الخالق، ووحدة المخلوق، ووحدة الحقيقة، ووحدة

\footnotetext{
${ }^{44}$ Ibid., p. 9-16.

${ }^{45}$ Ibid., p. 9-16.
} 
الحياة، ووحدة الإنسانية. 46 فهذه المبادئ الوجودية لها دلالاتا المعرفية والأخلاقية التي ينبغي أن توجه الفكر

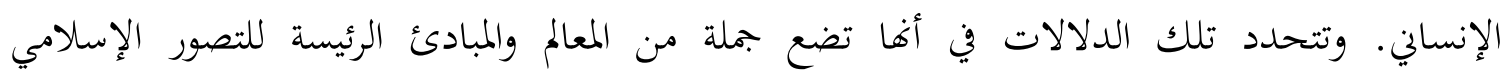
للمعرفة.

المبدأ الأول، يتعلق بوحدة المعرفة والصورة التي تظهر عليها. فالمعرفة في حقيقتها واحدة، لأن الحقيقة

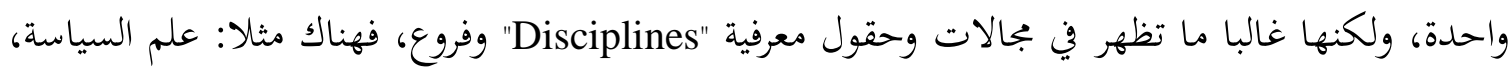

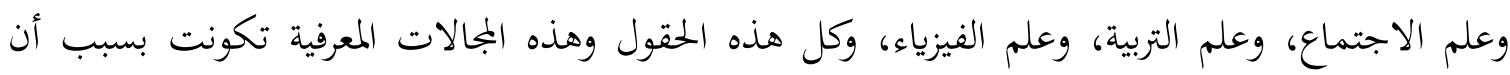

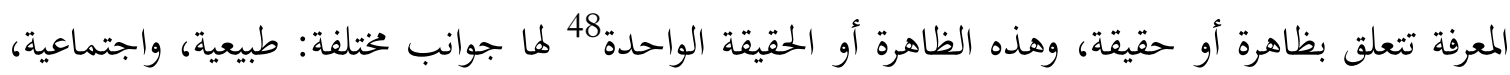
ونفسية، وأن دراسة هذه الجوانب تقتضي مثل هذه التقسيمات الإجرائية.

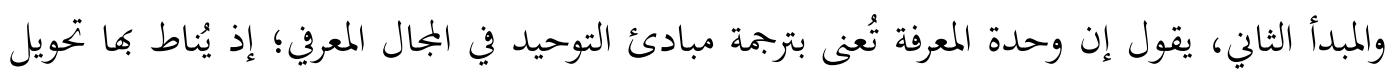
التوحيد من ججرد علاقة إدراكية، لثنائية عالمي الخالق والمخلوق، إلى محتوى معريف يصل الإنسان بربه. فمبدأ

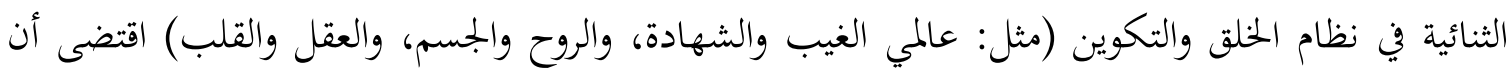

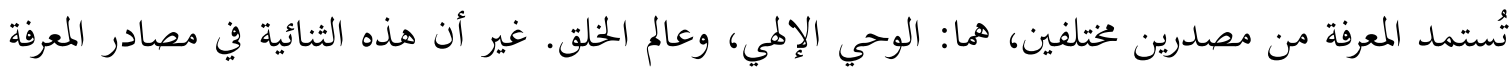

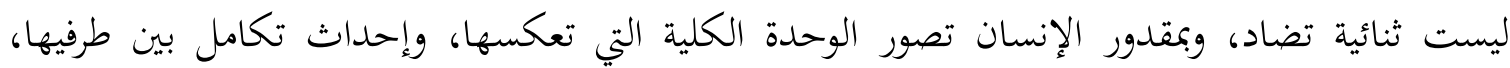
وذلك عن طريق تعقله للوحي واكتشافه لسُنن المخلق بشرط انقياده لأمر الله سبحانه. 49

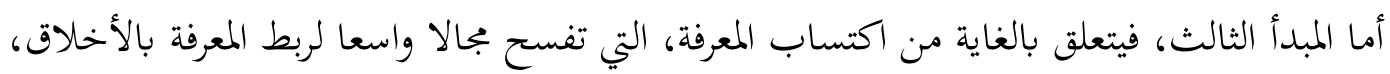

$$
\text { في إطار التفاضل القائم بين القيم الأخلاقية والقيم النفعية. }
$$

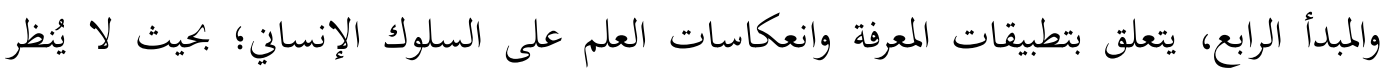

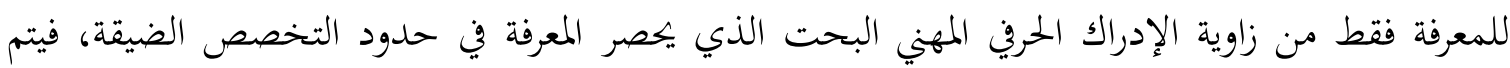
استيعاب المعرفة الإنسانية ضمن مهام الاستخلاف والأمانة.

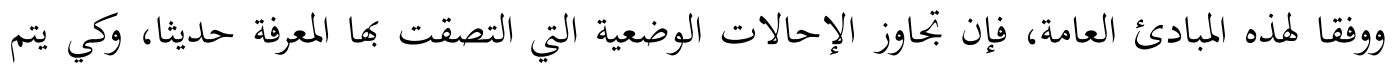

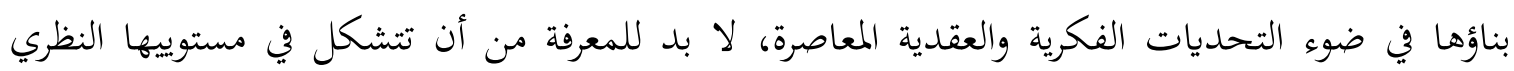

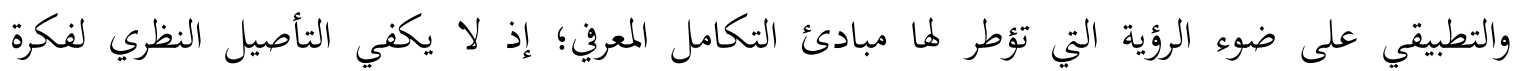

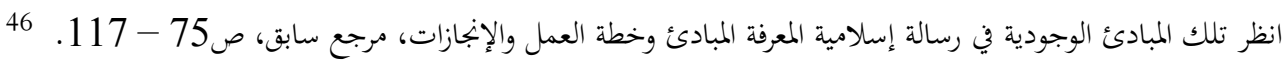

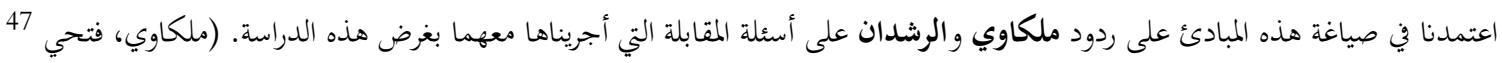

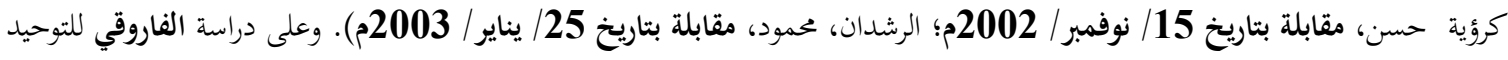
وجودية في المرجع التالي:
}

Al- Faruqi, Ismail Raji, Al-Tawhid: Its Implications for Thought and Life, Pp. 9 -16.

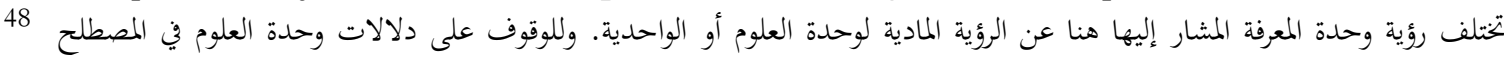

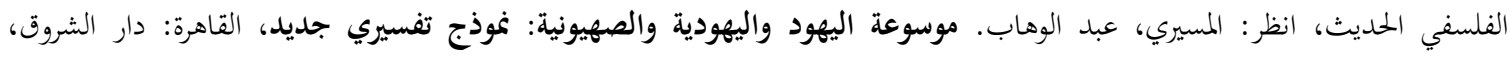
1999، ص238 (239-239.

العطاس، سيد محمد نقيب. مفهوم التعليم في الإسلام: إطار تصوري لفلسفة إسلامية للتعليم، مرجع سابق، ص65 - 69. 49 
التكامل، بل لابد من صياغة المعرفة والسير بتطبيقاتا في ضوء مبادئ التوحيد، حتى تظهر نتائج عملية

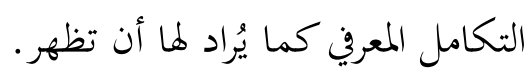
سواء في صورة مناهج جامعية أم برامج دراسية تتكامل فيها بنية موادها الداخلية من حيث تكامل

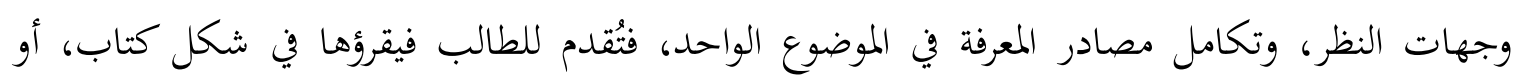
يسمعها على شكل محاضرة. يدخلُ في بنيتها مفهوم التكامل المعري. 50

\section{رابعا: مفهوم التكامل المعرفي وصلته بإسلامية المعرفة:}

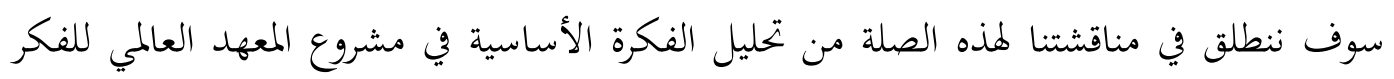

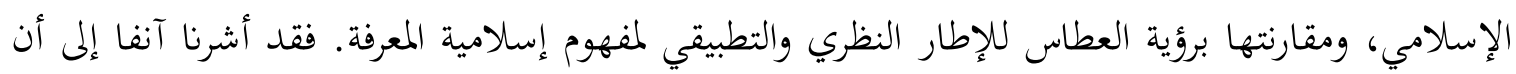

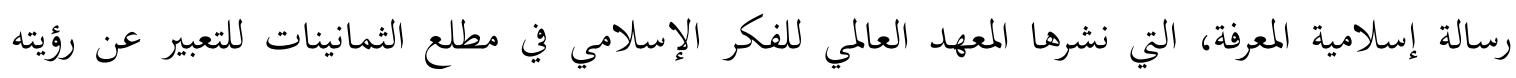

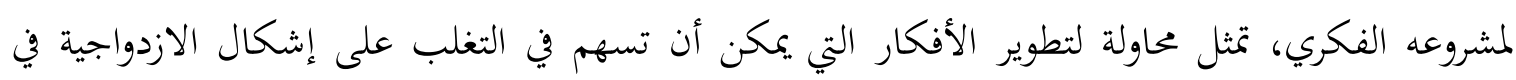

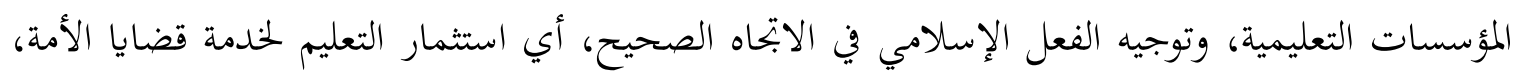

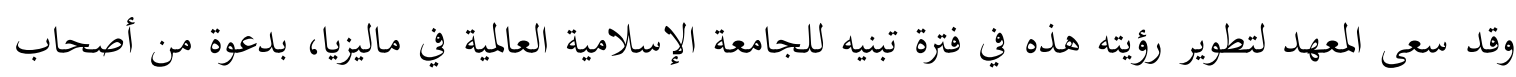

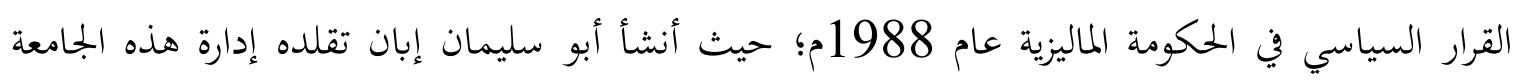

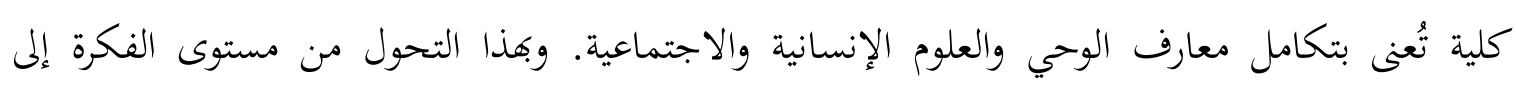

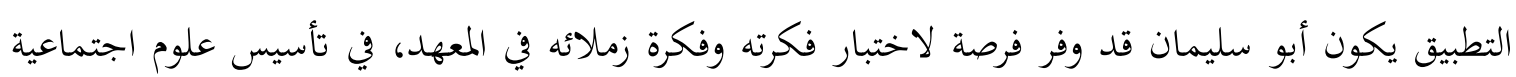
وإنسانية من منظور معارف الوحي. 51 إن الحديث عن "منظور معارف الوحي" يرتبط، فيما يبدو، بمحاولة تحرير العلوم الاجتماعية

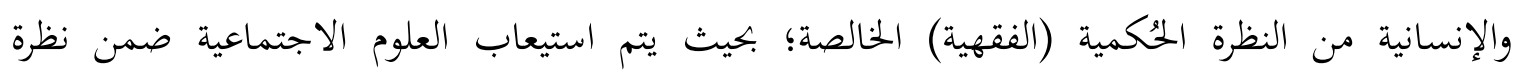

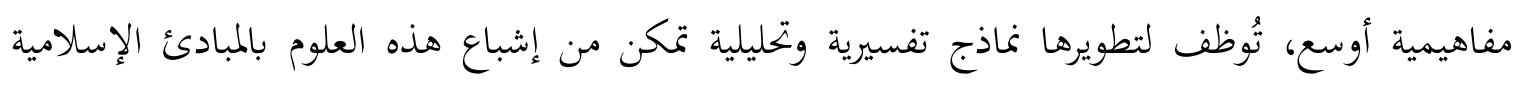

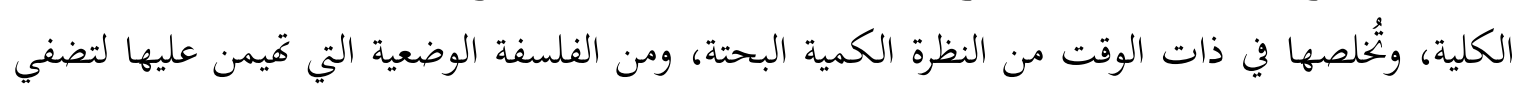
عليها الصبغة الإسلامية.

ومثل هذه المحاولة لا ينبغي أن تُوصف بأها "مقايسة للعلم على الفقه في الاستناد إلى الوحي"، كما

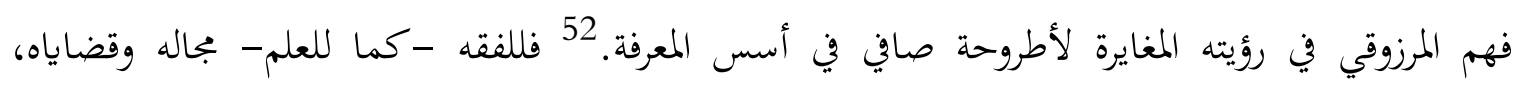

ملكاوي، فتحي المقابلة السابقة (بتصرف).

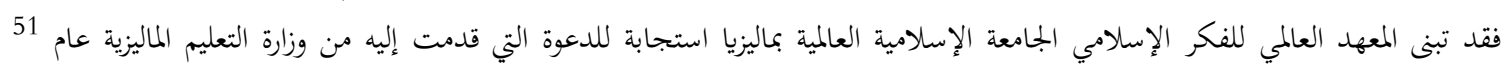

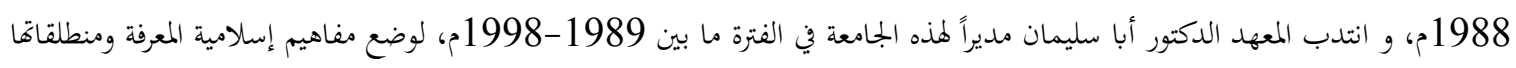

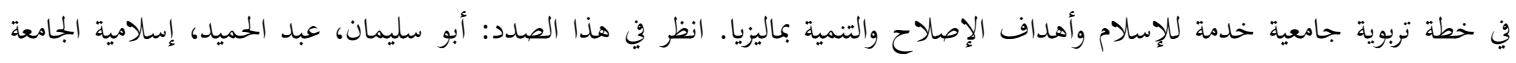

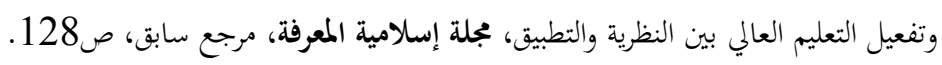

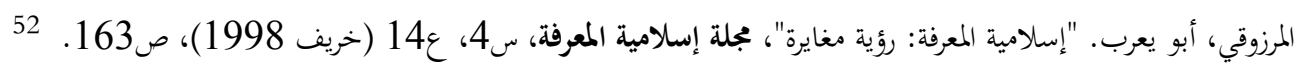


وتأسيس العلم على الوحي (القرآن والسنة الصحيحة) لا يضر، لا بالعلم ولا بالدين، بل هو تأسيس ضروري

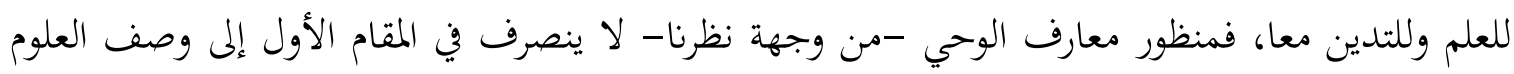

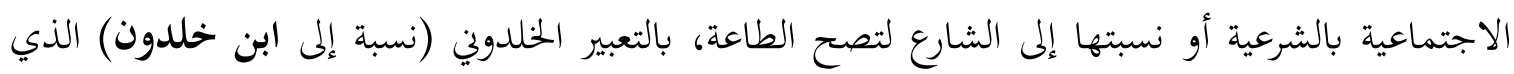

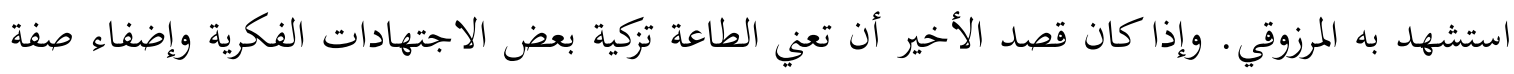

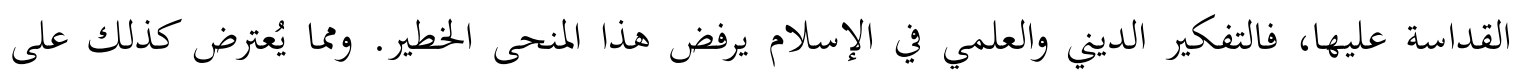

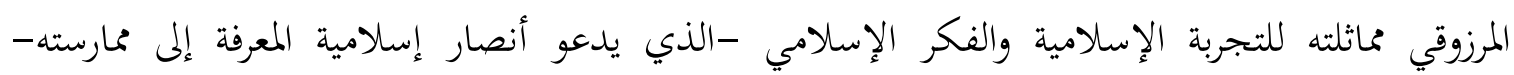

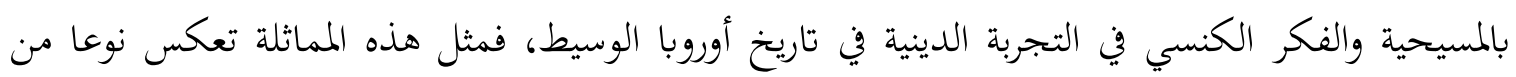

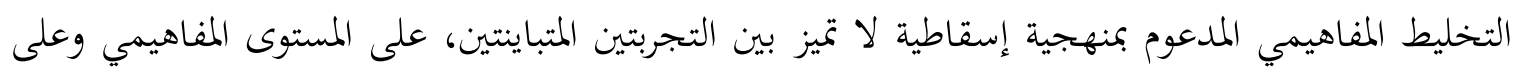
مستوى الممارسة الفكرية والدينية كذلك.

إن منظور معارف الوحي -على العكس تماما مما ذهب إليه المرزوقي- يريد أن يتخلص من النظرة

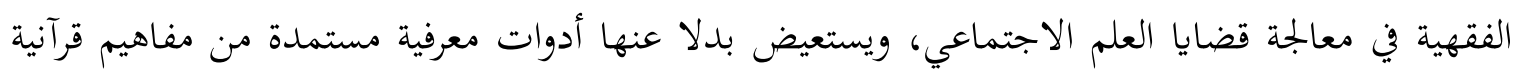

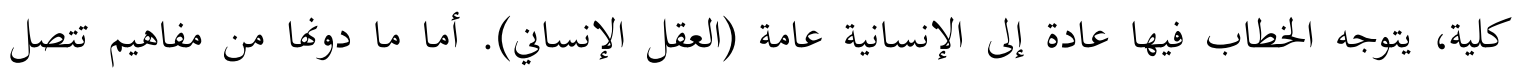

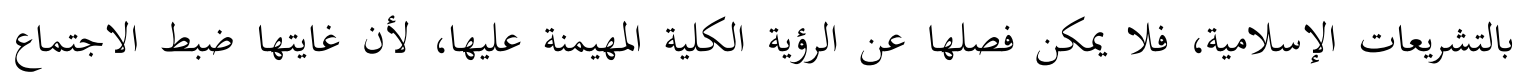

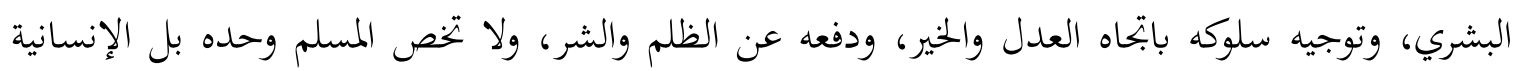

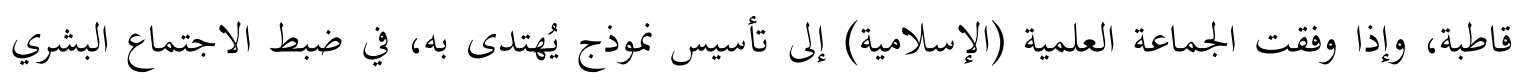

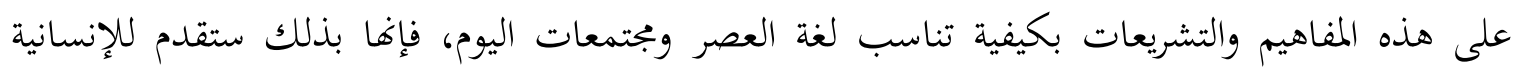

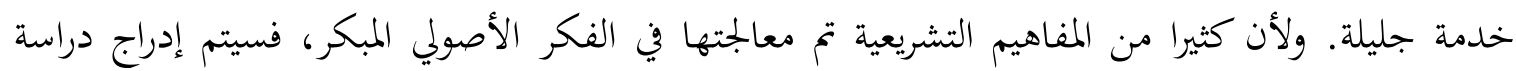

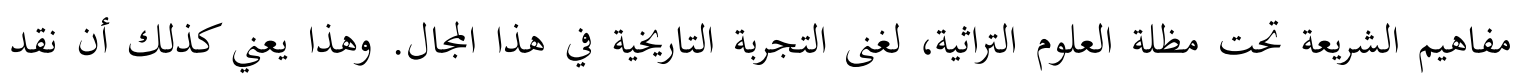

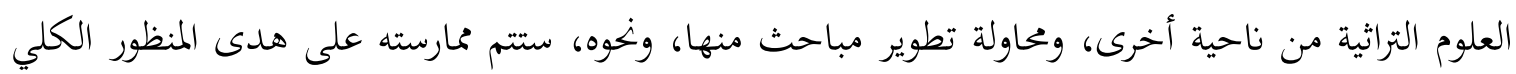

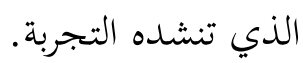

فالتمييز وارد بين مجال الفقه، وبجالات العلوم الاجتماعية عند من اشتغل بالتنظير فيما عرف

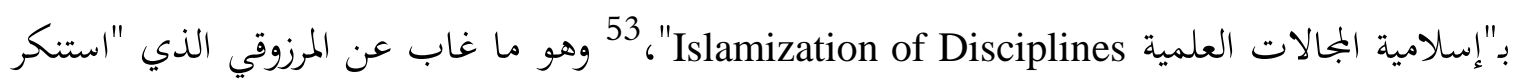

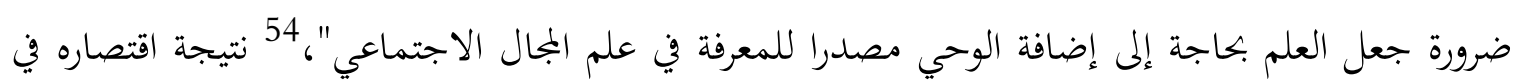

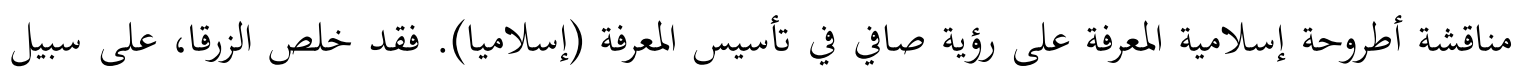

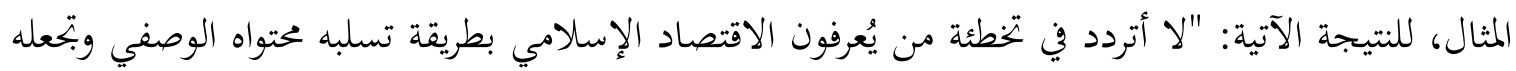

\footnotetext{
بنى الزرقا رؤيته في إسلامية علم الاقتصاد على هذا التمييز بمحاولته للإجابة عن سؤالين، أولما: ما العلاقة بين علم الاقتصاد العادي 53 الإداد

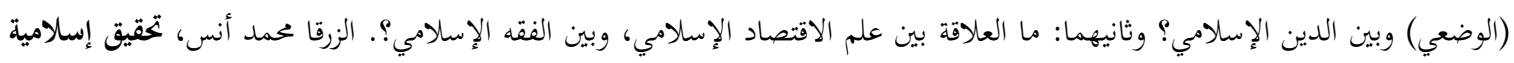

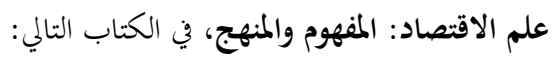

The International Institute of Islamic Thought: Toward Islamization of Disciplines, P. 317.

المرزوقي، أبو يعرب. "إسلامية المعرفة: رؤية مغايرة"، مجلة إسلامية المعرفة، مرجع سابق، ص148. 54 
مرادفا لفقه المعاملات"، 55 وذلك بعد أن بَينَ الفرق بين علم الفقه وعلم الاقتصاد الإسلامي، على أساس أن الأول: "هدفه الوصول إلى مقولات قيمية هي الأحكام الشرعية، وأن علم الاقتصاد الإسلامي -وكذا الوضعي- غايته الوصول إلى مقولات وصفية تُشخص الواقع، وتربط بين الظواهر الاقتصادية". 56 وهذا التفريق، كما أوضح الزرقا، تحف به استثناءات، منها: أن الفقه لا يخلو من بعض المقولات الوصفية التي ترد عند تعليل الأحكام أو بيان حِكمتها، وأن علم الاقتصاد لا يخلو تماما من المقولات القيمية. ولكن الأصل أن مثل هذه الاستثناءات "لا ينبغي أن تنسينا أن أهم مقومات الفقه هي المسلمات والأحكام الفقهية، وأن أهم مقومات علم الاقتصاد الإسلامي هو أنه علم وصفي". 57 ليس القصد في هذا المقام من الدراسة أن نتجه لتقويم مناقشة المرزوقي لأطروحة إسلامية المعرفة، وما أثارته من قضايا، ويكفي الإشادة هنا بما عكسه تقويم المرزوقي لأطروحة صافي، ومحاولة الأول تقديم رؤية مغايرة في فهم قضية إسلامية المعرفة من جدية في التناول غابت عن كثيرين ممن تبنوا عرض أطروحة إسلامية

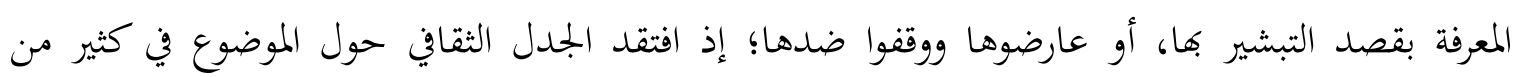
الأحيان صرامة النقاش العلمي الدقيق، نتيجة اختلاط المفهوم في مثل تلك المناقشات بقضايا لا تتصل به بصورة مباشرة. فقد ميز المرزوقي بين مستويين لإسلامية المعرفة، الأول يُعبر عن مشكل منهجية إدخال العلوم الحديثة في الممارسة الفكرية عند المسلمين عبر مؤسساقم التعليمية، وهو مشكل تربوي حضاري؛ والثاني يعبر عن مشكل معرفي فلسفي يتصل بإمكان جعل العلوم الحمديثة خاضعة لنظرة الإسلام للوجود. 58 فهذا التمييز مهم ومفيد لفهم أطروحة إسلامية المعرفة وتكاملها، أو تقويم ما أنتج في إطارها، ومناقشة تباين * الرؤى حولها داخل دائرة النخبة الداعية إليها. لقد أفضى مؤتمر مكة عام 1977م إلى أن حل المشكل التربوي- التعليمي، في البلدان الإسلامية، مرهون بحل المشكل المعرفي والفلسفي، فجاءت توصية المؤتمر الذي كان موضوعه "إسلامية التعليم" في ابتحاه أولوية العمل على "إسلامية المعرفة"59، واعتبار أسبقيتها التي ينبغي أن تحتلها في الجهود الإسلامية المعاصرة لتجاوز الأزمة الفكرية التي يعيشها المسلمون منذ قرون.

\footnotetext{
الزرقا، محمد أنس. تحقيق إسلامية علم الاقتصاد: المفهوم والمنهج ، مرجع سابق، ص333. 55

المرجع السابق، ص332.

المرجع السابق، ص332.

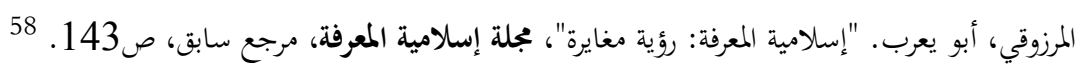

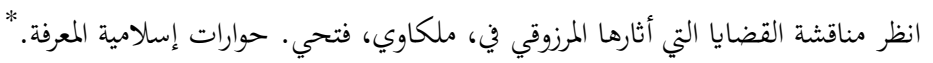

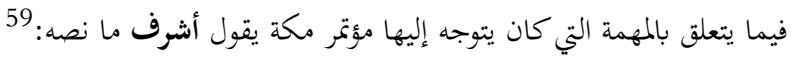

"The main aim of the conference was ... to Islamize education, and by Islamising we meant, not only to set up broad goals and ideas, but also to indicate the guidelines and the methodology...it did not (the conference) attempt to give a fully out Islamic alternative for all branches of knowledge. It decided to provide philosophical justifications for that alternative ". Ashraf, S. A., Islamic Education: An Evaluation of Past Conferences and Post Conference Achievements, In: Malkawi, Fathi (Editor), The Education Conference Papers, Vol. 1, Pp. 8 - 9. 
ويبدو كذلك أن هناك قفزة من مناقشة قضية الإسلامية على المستوى التعليمي إلى إشكالها الفلسفي، واعتبارها قضية معرفية- منهجية، بحجة أن المستوى الثاني مقدمة ضرورية لحل الإشكال التعليمي.

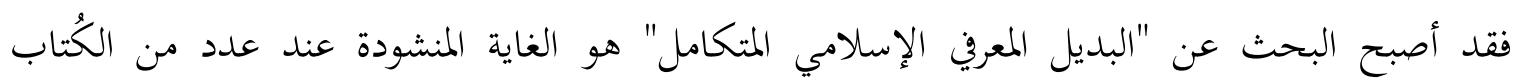
والمفكرين. وخلص بعضهم، كما في حالة أشرف على سبيل المثال، إلى استحالة إمكان التقارب بين نظامي التعليم: العلماني الغربي والإسلامي التقليدي؛ فلسفيا ومنهجيا. واشترط توافر المعرفة الإسلامية (البديلة) في كل المجالات المعرفية قبل الشروع في بتربة التعليم الإسلامي المتكامل. 60 واتساقا مع ما سبق، فإن إنشاء كلية لمعارف الوحي والعلوم الإنسانية إبان تبني المعهد العالمي للفكر الإسلامي لإدارة مؤسسة جامعية بماليزيا، تُعنى بتطبيق فلسفة إصلاح التعليم الإسلامي من منظور رؤية إسلامية المعرفة، يُعَد حدثا مهما سيُوظف في النقاش التالي لتحليل مفهوم إسلامية المعرفة بمعنى مرادف للتكامل المعرفي وإسلامية التعليم؛ بحيث تكون غايته إدخال العلوم الاجتماعية الحديثة في الممارسة الفكرية بمؤسسات التعليم الإسلامي، على اعتبار أن هذا (الإدخال) وتلك (الممارسة) شرطٌ ضروري ومقدمة لازمة لولادة علوم اجتماعية إسلامية النشأة.

وفي هذا السياق، ينبغي النظر في تجربة أبي سليمان في إدارة هذه الكلية والجامعة عموما، على أها تسير في ابحاه مغاير لمبدأ أشرف الذي اشترط توافر المعرفة الإسلامية المتكاملة قبل الشروع في بتربة إسلامية التعليم. فالاختلاف بين الرؤيتين ليس اختلافا في المنهج فحسب، ولكنه اختلاف في النظرة للمفهوم. وسينبه التحليل الآتي إلى موقع العلوم الإسلامية التراثية في مشروع إسلامية المعرفة، عندما يستخدم هذا المفهوم بمعنى مرادف للتكامل المعري؛؛ بقصد دعم فكرة منظور معارف الوحي الذي يوفر أداة منهجية لتقويم التراث الإسلامي وعلومه، إضافة إلى ميزته الأساسية التي تفترض أن المنظور سيبلور رؤية إسلامية كلية تنتقد بها العلوم الغربية وتقوم، وهي خطوة لازمة لتوطينها في الرؤية الإسلامية. ولما كان لأبي سليمان الدور الأكبر في تأسيس كلية معارف الوحي والعلوم الإنسانية، 61 في عام 1990م، فإنه من الأهمية بمكان أن نبدأ بعرض تصور صاحب فكرة إنشاء هذه الكلية لمفهوم التكامل المعرفي، الذي ارتبط ارتباطا لصيقا بالجهود التي بذلت

نص ما قاله أشرف في هذا السياق: 60

'Unless we are able to formulate all basic concepts of knowledge from the point of view of Islamic metaphysics, we shall not be able to establish an Islamic university'. Bilgrami, H. H. and Ashraf, S.A., The Concept of an Islamic University, P. viii.

the master plan "

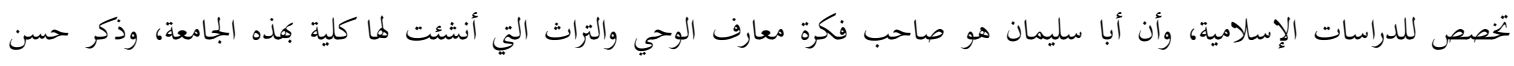

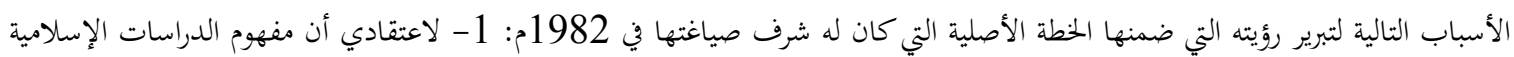

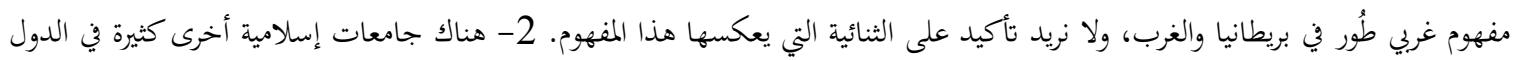
العربية تتخصص في هذا المجال، والأفضل أن يذهب الطلاب إلى هناك ليتخصصوا في بيئة تساعدهم على تعلم اللغة العربية وإجادةقا. 3- كانت

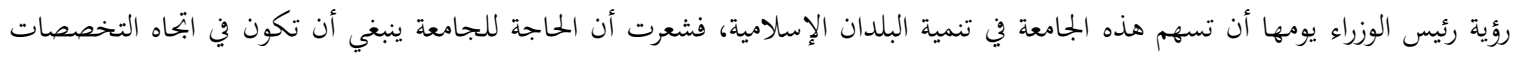
التطبيقية وربطها بالمنظور الإسلامي. حسن، محمد كمال، المقابلة السابقة. 
في الجامعة الإسلامية العالمية بماليزيا. لا سيما وأن أبا سليمان يعتبر أن: "وجه التميز في الجامعة الإسلامية العالمية بماليزيا أوضح وأجلى ما يكون في كلية معارف الوحي والعلوم الإنسانية؛ حيث كان الاسم في حد

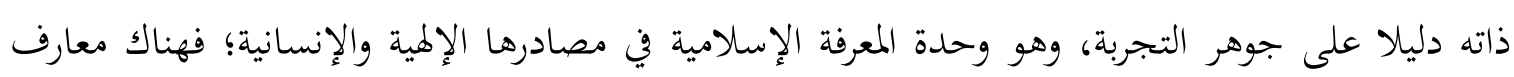
الوحي، وهناك العلوم الإنسانية؛ حيث إننا لا يمكننا أن ندرك حقيقة دلالات التوجه والهدي الإلهي دون معرفة الطبائع، والوقائع في الإنسان وفي الكائنات؛ كما أنه لا يمكننا الإسهام في العمل على هداية الحياة الإنسانية وممارستها وتسخيرها ورعايتها للكون والكائنات، إلا إذا اهتدت هي ذاتها بقيم الشريعة ومقاصدها ومبادئها الكلية الصادرة عن الخالق الحكيم العليم". 62 والحديث في النص السابق ليس عن معارف للوحي في جانب معرفة إنسانية من منطلق التقارب، والتجاور، والمقارنة؛ ولكنه عن تكامل لتلك المعارف والعلوم وفق "خطة عمل مبنية على أن هناك أهدافا ومقاصدَ ومنطلقات للأمة يجب الانطلاق منها نحو التحديات والآفاق المتاحة"... ولذلك فإن الجانب الأكاديمي في الجامعة يجب أن يبُنى على أفضل التصورات الأكاديمية. ويجب أن أن النهات يُبنى على أساس التزام العلم بالكليات الإسلامية، والمنهجية العلمية، والتجريبية، ومن خلال الأساليب الإبداعية التي تؤدي إلى تكامل المعرفة الإسلامية من: الوحي، والعقل، والطبائع، والوقائع. وتنتهي باستعادة الرؤية الإسلامية، وتنقية الثقافة، وتصحيح أساليب التربية، وتكامل المعري والمنهجي، والفردي والجماعي في بناء الإنسان المسلم. ويحدد أبو سليمان ما يعنيه بمفهوم التكامل المعريف وأبعاده التطبيقية بصورة أوضح في قوله: يتكون التكامل المعرفي أكاديميا من دراسات ومساقات لخدمة فهم الوحي، وتوثيقه وضبطه، وإمداد صاحب كل اختصاص في بجاله المعرفي- سواء أكان اجتماعيا أم إنسانيا أم ماديا- بالمقاصد، والمفاهيم، والمبادئ، والقيم، والتصورات، والضوابط الكلية اللازمة لكل مجال وفرد، ولكل صاحب اختصاص، بهدف توفير لوازم الإنتاج العلمي الحضاري الصحيح الراشد". 64

ويؤكد أبو سليمان، في المقابلة التي أجريناها معه لغرض هذه الدراسة، وفي بحوثه ودراساته الأخرى، في تصوره لإسلامية المعرفة أو تكاملها على ثلاثة أمور: أولها: التفاعل الإيجابي مع الواقع، وعدم الانطلاق من مجردِ فكرٍ نظري فلسفي بتريدي، أو مجرد استلهام لتصورات، وخُطط مسبقة؛ بحيث ينقاد لها الفكر لإِ (الإسلامي) ويترسم خُطاها، فطاقات الفكر والدرس والبحث في الطبائع والوقائع تنطلق على أساس مبادئ العقل، وسنن الكون، ومقتضى هداية الوحي. وثانيها: إن إسلامية المعرفة، أو تكاملها، عملية تتطلب الإلمام بمفاهيم الإسلام، وقيمه وبالمعرفة الحديثة، والتفكير المستمر لتوليد الفكر والمعارف الإسلامية. وثالثها: أن إن إن إنها إسلامية المعرفة أو تكاملها ليست عملية معرفية بحتة، ولكنها عملية نفسية تربوية تعمل على تنمية الدوافع،

\footnotetext{
أبو سليمان، عبد الحميد أحمد: المقابلة السابقة. 62

المرجع السابق. 63

المرجع السابق.64
} 
وتربية الوجدان، وترير العقل المسلم من آفات الخرافات، والأوهام، والتناقضات؛ ليخوض غمار العلم والمعرفة في شجاعة وثقة ومبادرة؛ طلبا للإصلاح والإتقان، والإبداع. إن النقاط السابقة، التي يمكن استخلاصها من رؤية أبي سليمان لإسلامية المعرفة أو تكاملها (وهو ترادف أكده كثيرا في المقابلة آنفة الذكر)، هي عينها التي أكدها البوطي في بحثٍ اعتبره صافي -وفق مناقشة

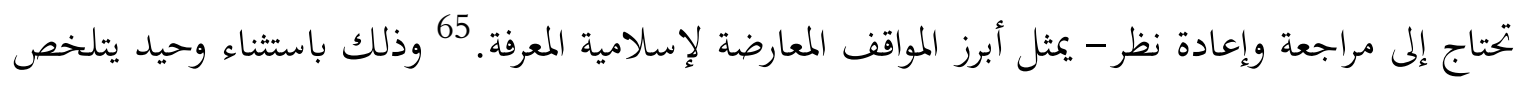
في أن البوطي أبدى تحفظه على ما أسماه "شعار أسلمة المعرفة". وقد انتهى البوطي إلى هذا الاعتراض بعد أن شرح أزمة المعرفة في ظل الحضارة الحلديثة بوجه يتفق تماما مع رؤية الداعين إلى إسلامية المعرفة، غير أنه عول كثيرا على تزكية النفس لتجاوز هذه الأزمة، واعتبرها العلاج الأول لحل الأزمة المعرفية الحلديثة وتقديم المعرفة الصافية الصحيحة. فالتزكية تعني "ترويض الوجدان الإنساني ابتغاء تطويعه لمقتضيات القرار العقلي". 66 وعند التدقيق في رؤية البوطي لأزمة المعرفة المعاصرة وعلاجها، يتضح أنه لا يعترض على مشروع العائه المعهد العالمي للفكر الإسلامي، بالوجه الذي أظهرته دراسة صافي. 67 فاعتراض البوطي يتلخص في رفضه لماولة فرض تحيز على النشاط المعري للفكر، ويقول بـ"أسلمة النفس" لا "أسلمة المعرفة" على مستوى المصطلح والعنوان. والاعتراض الأخير لفظي إصطلاحي، وقد أثاره غيره من المفكرين والأساتذة والباحثين، ممن لمم إسهام مقدر في الفكر الإسلامي المعاصر، ويشاركون أصحاب التوجهات الفكرية الإسلامية محل النقاش ذات القناعات على الرغم من تحفظهم على العنوان الذي عرف به هذا الاتحاه الفكري بين المعاصرين. 68 ويبدو أن مصطلح "إسلامية المعرفة"، بالفعل، قد كلف المشتغلين في مشروعه الفكري -خاصة في فاية الثمانينيات، وكامل عقد التسعينيات من القرن المنصرم- عقدَ محاضرات وندوات ومناقشات لأجل رفع الغموض عنه وشرحه بحيث لا يلتبس بضرب من التفكير الديني العقيم، أو تتم مقاربته بالتجربة الغربية الكنسية التي قادت إلى جانب كبير من الأزمة الفكرية المعاصرة. إذن؛ فقد انتهى البوطي إلى أن الإسلام يمتلك في عقائده ونظمه حل الأزمة المعرفية المعاصرة، واعتبر أن ترويض الوجدان الإنساني ابتغاء تطويعه لمقتضيات القرار العقلي المرحلة التحضيرية التي لا بد منها بين يدي أي عمل فكري. 69 ولذذا الاعتبار نرى الإنساء

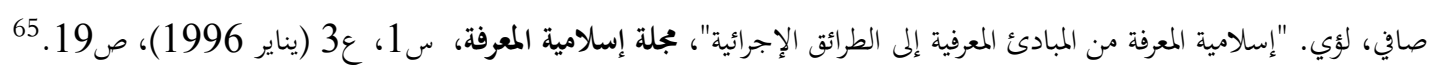

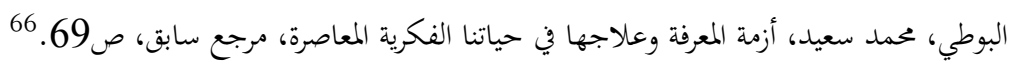

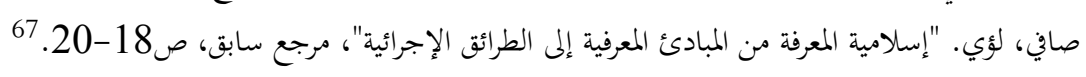

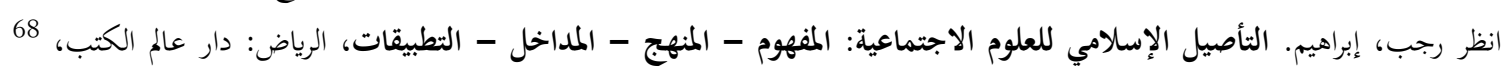

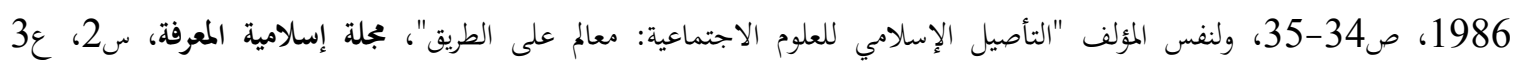

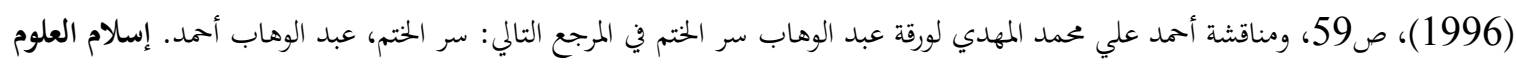

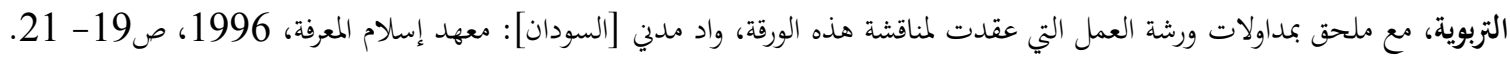
البوطي، محمد سعيد. أزمة المعرفة وعلاجها في حياتنا الفكرية المعاصرة، ص69. 69 
أن هناك ثمة توافقا بين رؤيتي البوطي وأبي سليمان في قضية تكامل البعدين المعريف والوجداني وأهميتهما في طرائق التفكير.

إن ما يعبر عنه كلٌ من البوطي وأبي سليمان، لا يعني أن الإنتاج المعريف المرتقب تحت مظلة هذا

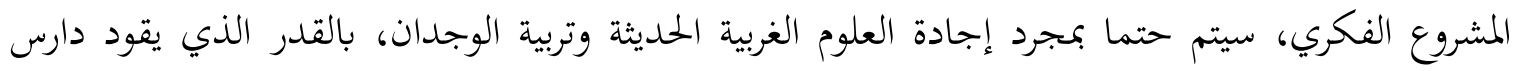

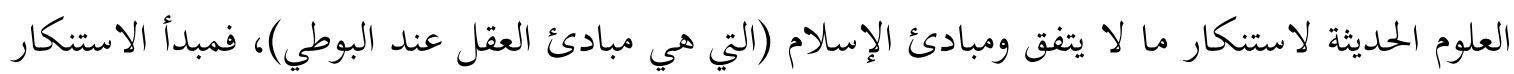

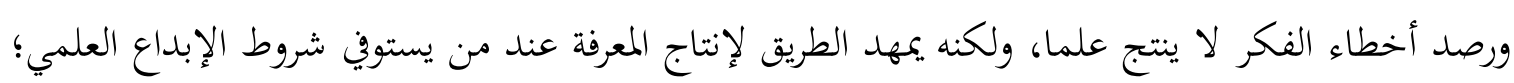

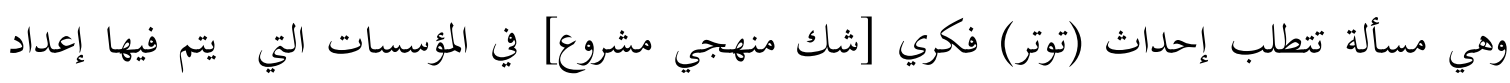

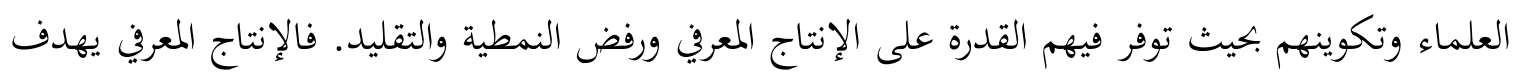
- ضمن ما يهدف- إلى تحاوز الانقطاع الحضاري الذي وقئ وقع في تاريخ الأمة الإسلامية.

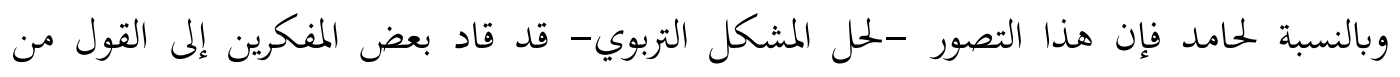

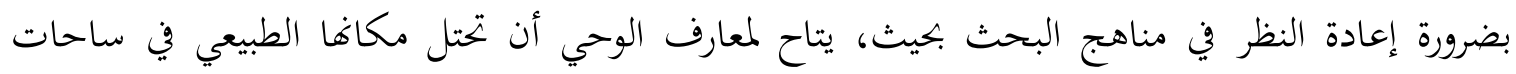

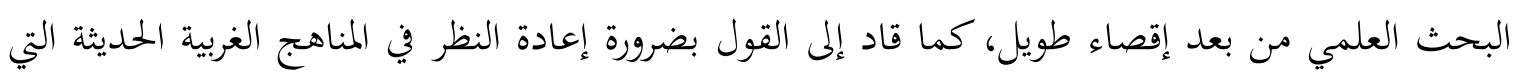
تولدت خارج الإطار الديني.

وبناء عليه فإن حامد يذهب إلى أن التكامل المعرفي -حتى في مستوياته العلمية الخاصة- لابد أن

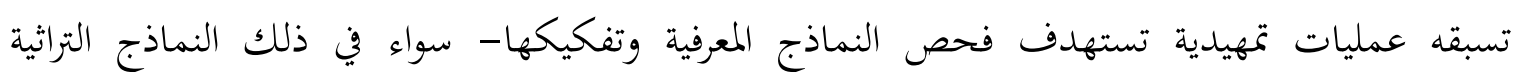

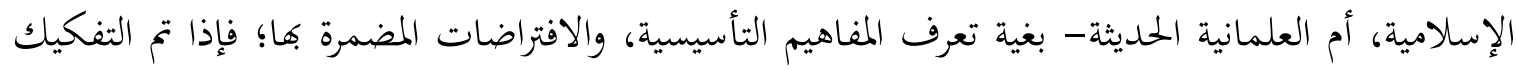

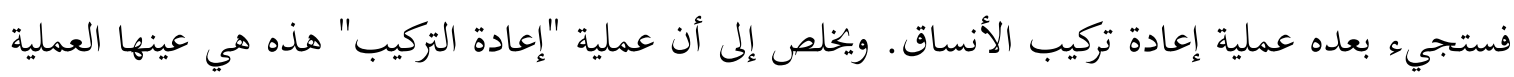

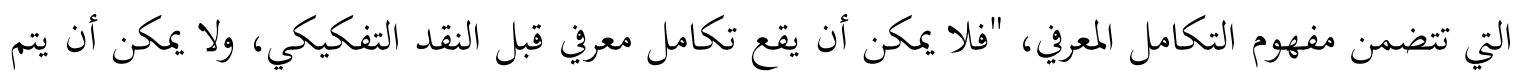

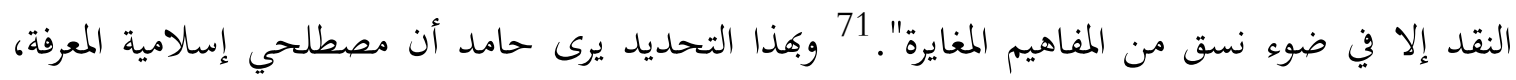
وتكامل المعرفة يشيران إلى مفهوم واحد.

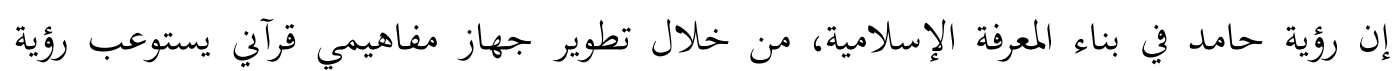

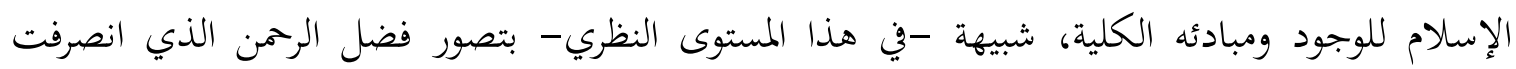

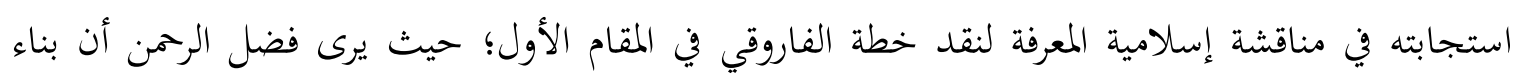

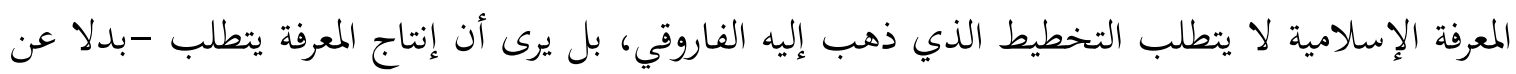

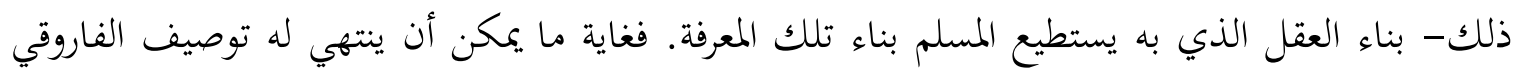

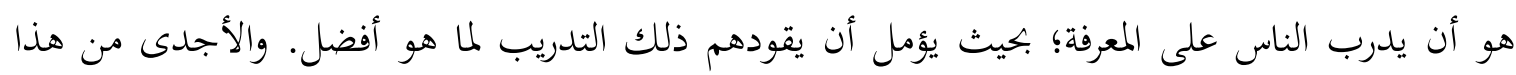

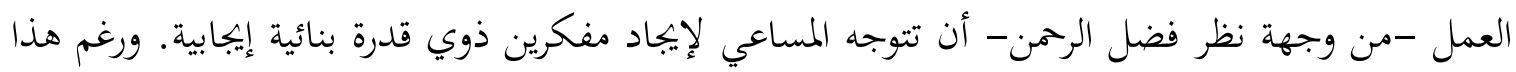

\footnotetext{
حامد، التجاني عبد القادر، مقابلة بتاريخ 18 نوفمبر 2002.
}

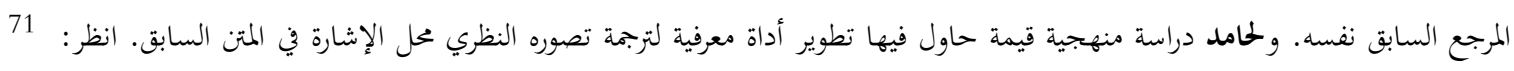

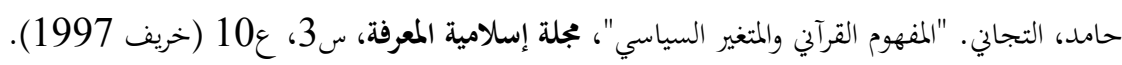


الاعتراض على خطة عمل الفاروقي لإسلامية المعرفة فإن فضل الرحمن يذهب إلى أن الغرب الحميث قد

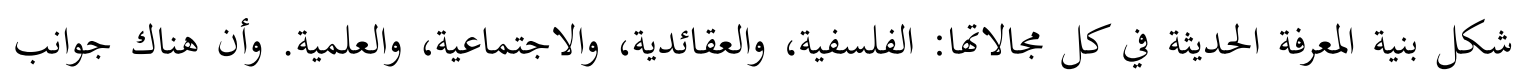
من هذه المعارف مقبولة في النظرة القرآنية، كما أن هناك جوانب أخرى يرفضها القرآن جملة. 72 ولأن المسلمين في العصر الحديث قد وجدوا أنفسهم في تحد مع الغرب، فإن فضل الرحمن يقدم التساؤل التالي ليخلص إلى رؤية قريبة من رؤية حامد التي فرغنا من تحليلها. فيتساءل فضل الرحمن: هل يمكننا أن نواجه

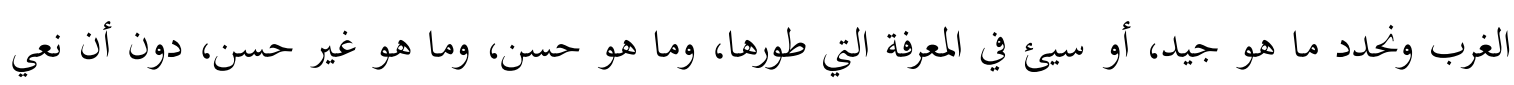
ذاتنا؟ وبهذا السؤال يمهد فضل الرحمن للحاجة لمراجعة ونقد العلوم الإسلامية التقليدية، التي تحتوى عنده بالتأكيد على كثير من الأشياء الإسلامية، وكثير من الأشياء غير الإسلامية، وكثير مما هو وسط بين ما هو إسلامي، وما هو غير إسلامي. ويدعو لتأسيس مثل هذا النقد على القرآن الكريم، الذي تستمد منه معايير النقد والتقويم. ومثل هذا النقد للتراث الإسلامي في غاية من الأهمية في تصور فضل الرحمن، وذلك لأن هذا النقد يمثل تمهيدا ضروريا لنقد المعرفة الحلديثة. "فدون اختبار معرفتنا التراثية وتقاليدنا العلمية جيدا لا يمكننا

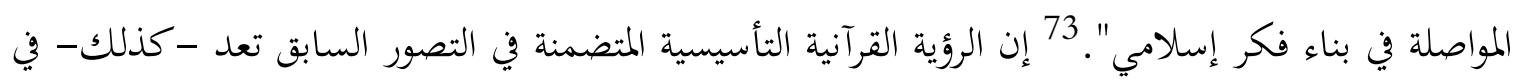
غاية من الأهمية عند صافي، ولكن ليس كأداة لنقد العلم الإسلامي التقليدي أو العلم الحديث، بل لفهم السلوك الإنساني والحياة الإنسانية.

وبالرغم من أن صافي عرف التكامل المعرفي بأنه: "محاولة لتحقيق تكامل معرفي بين الوحي والخبرة البشرية"، 74 إلا أنه اعتبر الحديث عن الوحي في مقابل الخبرة البشرية يعكس نوعا من عدم الدقة؛ من منطلق أن القرآن إلى جانب أنه يحتوى على الثوابت والقيم الكلية، فإنه في ذات الوقت يتضمن إخبارا عن خبرات بشرية سابقة يمكن الاهتداء بها. ولكن هذا التحفظ الذي ذهب إليه صافي فيه نظر؛ لأن تلك الخبرات لورودها في الوحي اعتبرت جُزءا منه، فطريقنا لمعرفتها هو الوحي، وليس الخبر الإنساني المخض. ويبدو مما سبق أن الإلمام بمفاهيم وتصورات العلوم الإسلامية والعلوم الإنسانية والاجتماعية الحلديثة، قد أصبح -بمنظور توجهات إسلامية المعرفة- شرطا أساسيا لأي محاولة جادة تضطلع بترجمة المفهوم، باعتبارها الغاية النهائية له. وقد أكدت خطة العمل التي اقترحها الفاروقي لإسلامية المعرفة أهمية المحافظة على التراث المنهجي

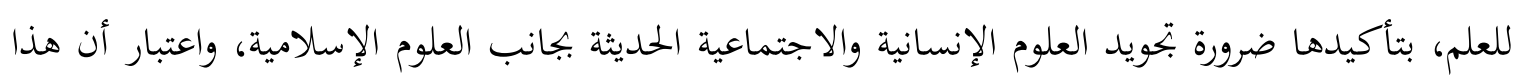

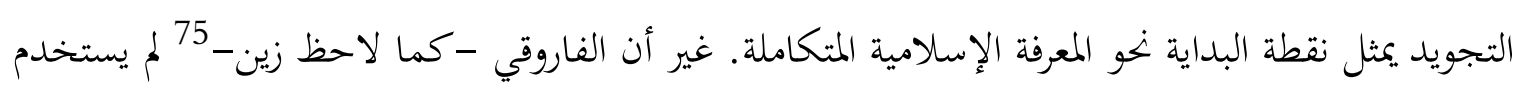
مفهوم التكامل في التعبير عن هذه العملية، بل استخدم تعبير "التركيبة الخلاقة Creative Syntheses". 76

${ }^{72}$ Fazlur Rahman, Islamization of Knowledge: A Response, The American Journal of Islamic Social Science, ${ }_{2}$ Vol. 5, No. 1, 1988, P. 5.

${ }_{73}^{73}$ Ibid., p. 10-11.

صافي، لؤي، المقابلة السابقة. 74

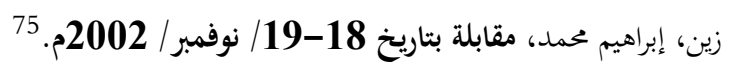

${ }^{76}$ Faruqi, Isma'il, Islamization of Knowledge: General Principles and Workplan, P. 44. 
وقد نَبَ زين - الذي تقلد في كلية معارف الوحي والعلوم الإنسانية مناصب إدارية رفيعة في عقد التسعينات المنصرم- إلى أن مفهوم التكامل المعرفي قد تم نحته وتطويره في التجربة الماليزية في مجال التعليم الجامعي الإسلامي، وأنه وصف للجانب التطبيقي لمفهوم إسلامية المعرفة في الحقل التعليمي والتربوي. ويشير زين، 77 إلى أن التكامل المقصود لا يعني الجمع بين ضدين لا يلتقيان إلا على سبيل طرح أحدهما، ولكنه يعني الأخذ بالحممة أيا كان مصدرها، وينبه إلى أن التكامل المعرفي: "لا يعني الترجمة غير الواعية عن غيرنا، بل تَثَل ما عند الآخر وهضمه حتى يصبح جزءا من الحضارة الإسلامية وبنية الفكر الإسلامي". ويؤكد زين ضرورة أن يقوم علماء المسلمين كله في مجال معرفته، بالكشف عما أصاب المعرفة من انحراف عن توجهات التوحيد (حتى يكونوا شهداء على الناس)، كما ينبغي للمسلم أن يكون واعيا حال استخدامه لمناهج، وأدوات طُورت في خارج الإطار الديني.

\section{خامسا: مفهوم الجمع بين القراءتين:}

لعل المناقشة السابقة قد أظهرت أن هناك علاقة تداخلية وتكاملية بين مفهومي التكامل المعرفي، وإسلامية المعرفة لدى قطاع عريض من دعاتما والعاملين فيها. كما أظهرت المناقشة أن تلك العلاقة أسست لما التوجهات الفكرية الإسلامية التي عبر عنها المفهومان في إطار المحاولات الرامية إلى إعادة النظر الجِدي وبمنهجية محددة (قائمة على الثوابت والقيم الكلية التي تجسدها المفاهيم القرآنية التأسيسية) في النظام المعرفي (التعليمي/ التربوي) السائد. ووفقا لهذه الرؤية، فإن خطة العمل التي اقترحها الفاروقي، التي تنتهي في شكلها

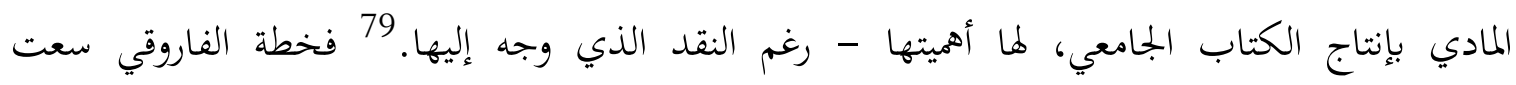
للمحافظة على التراث المنهجي للعلم، ولكنها اعترضت على الرؤية الوضعية التي ألبستها التجربة الغربية المعرفةً الإنسانية، وعولت كثيرا على إبداع الباحث المسلم لتجاوز تلك الرؤية، وفقا لعملية تفكير تعتمد التحليل والتركيب الخلاق بين المعرفة الإنسانية ومعارف الوحي. 80 وإن كانت هذه العملية الذهنية قد تد حددت حلقتها الأخيرة في إصدار الكتاب الجامعي الذي يُعبر عن الرؤية الإسلامية المتكاملة في شتى حقول

77 Ibid., p 44.

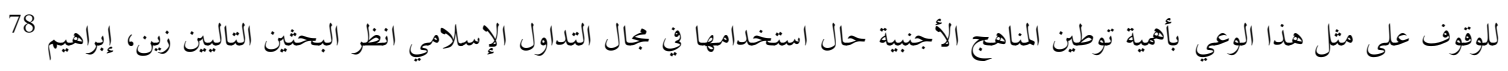

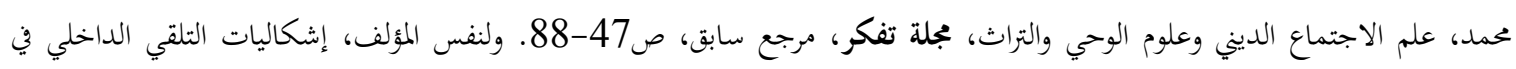

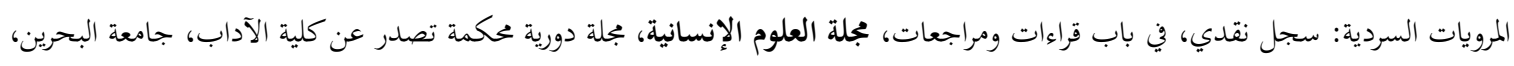

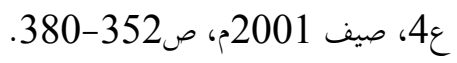

انظر في هذا الصدد صافي، لؤي. "إسلامية المعرفة من المبادئ العامة إلى الطرائق الإجرائية"، مجلة إسلامية المعرفة، مرجع سابق، ص40-79 صيف 45؛ والدراسات التالية:

Fazlur Rahman: Islamization of Knowledge: A Response, Pp. 8 - 11. And Yasien, Mohamed: Islamization of Knowledge: A Critique, the American Journal of Islamic Social Science, Vol. 11, summer 1994, P282 $-293$.

${ }^{80}$ Faruqi, Isma' il, Islamization of Knowledge: General Principles and Workplan, P. 38 -48. 
المعرفة وميادينها، فذلك لأن رسالة الفاروقي قد ربطت المشكل المعري عند المسلمين بأزمة النظم التعليمية في البلدان الإسلامية، والمتمثلة في ازدواجية التعليم.

في المناقشة التالية سيُنظر إلى التحول الذي أحدثه العلواني، منذ بداية التسعينات، في خطة العمل على أنه يمثل نقلة نوعية في فكرة إسلامية المعرفة، قصد منها بحاوز رسالة إسلامية المعرفة: المبادئ وخطة

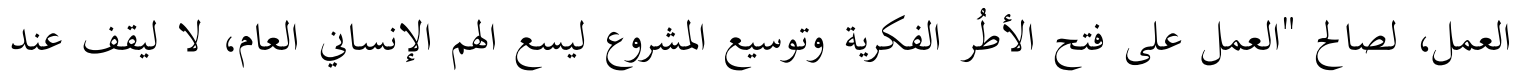

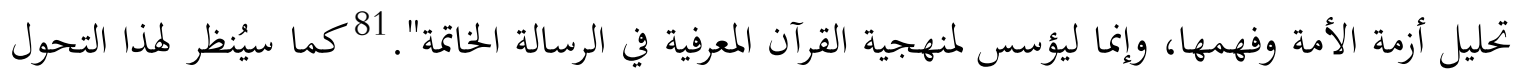
على أنه انتقال بالفكرة من مناقشتها على مستوى الإشكال التعليمي- المعرفي، إلى اعتبارها هما كونيا فلسفيا يتطلب الوعي بالدور الرسالي للأمة الخاتمة، "صاحبة منهجية الجمعع بين القراءتين". ولهذا الاعتبار، فإن رؤية العلواني لإسلامية المعرفة تختلف في كثير من جوانبها التفصيلية عن الرؤية التي يمكن تحديدها على ضوء المناقشة السابقة للعلاقة بين مفهومي التكامل المعري وإسلامية المعرفة. ويمثل البحث الموسوم "أصول الفقه: منهج بحث ومعرفة"82الرؤية المبكرة للعلواني في التعامل مع قضية إسلامية المعرفة، على أساس أها تتحدد في وجوب اتخاذ الوحي مصدرا للمعرفة. والموضوع الأساس الذي أراد العلواني تأكيده عليه في هذا البحث، أن اتخاذ الوحي مصدرا للمعرفة يتطلب أن يكون هناك منهج للتعامل مع الوحي الذي سيتناول ظواهر اجتماعية وإنسانية، وأن المسلمين لديهم شيء من هذا المنهج فيما عرف "بأصول الفقه". ولكن يبدو أن العلواني الذي ظل ينادي بفكرته هذه طوال عقد الثمانينات، قد اقتنع فيما بعد بوجاهة الاعتراضات على مد منهج تم تأسيسه في الأصل لمعالجة القضايا الفقهية- التي تتسم بالجزئية في الغالب- لكي يكون صالحا لمعالجة الظواهر الاجتماعية أو الإنسانية العامة، بقصد معرفة القوانين والسنن التي تحمها. 83فقد انصرف العلواني منذ بداية التسعينات إلى الحديث عما أسماه حاج حمد "الجمع بين القراءتين"، 84على أساس أنه يمثل المنهجية المطلوبة في التعامل مع الوحي على مستوى العلوم الإنسانية، والاجتماعية، والطبيعية". فلم يعد كافيا لمواجهة متطلبات حركة الإسلام تجاه العالم، أو حركة العالم بتحاه الإسلام ذلك التطوير المحدود الذي ترتفع به بعض الأصوات من حين لآخر لتطوير علم الأصول، وجعله أداة منهاجية طيعة في يد الفقيه المعاصر، ذلك أن الفقيه ذاته قد صار بحاجة إلى كثير من العلوم الاجتماعية

زين، إبراهيم محمد. "إصلاح الفكر الإسلامي: مدخل إلى نظم الخطاب في الفكر الإسلامي المعاصر"، مجلة إسلامية المعرفة، س2، ع6 81 (سبتمبر 1996)، ص137 - 147.

العلواني، طه جابر. أصول الفقه الإسلامي: منهج بحث ومعرفة، فرجينيا: المعهد العلمي للفكر الإسلامي، 1995، مرجع سابق. 82

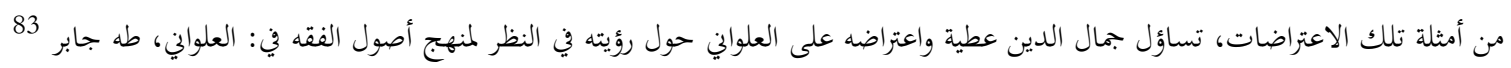

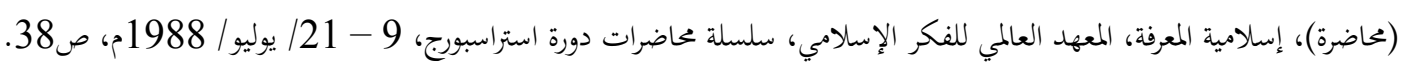

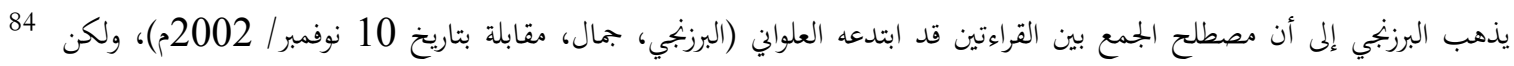

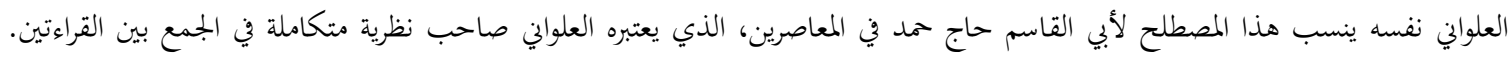

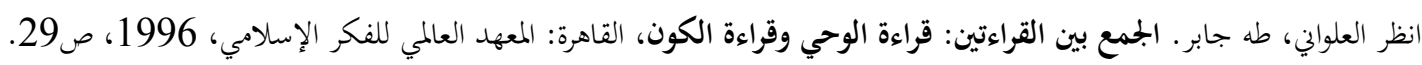


والإنسانية المعاصرة، إضافة إلى بعض قضايا العلوم الطبيعية، ودون ذلك لن يتمكن الفقيه من معالجة شؤون، وشجون العصر". وعلى الرغم مما قيل، أو يمكن أن يُقال، عن تأثير حاج حمد على العلواني وطريقة إدارته لمشروع إسلامية المعرفة في عقد التسعينات المنصرم، فإن الأخير قد عبر عن رؤيته للجمع بين القراءتين بطريقة يعترض الأول على جوانب منها، مما يعني أن بين الرؤيتين اختلافا حول تصور المفهوم ذاته. لقد ظهرت بدايات النقلة النوعية في طرح فكرة إسلامية المعرفة على يد العلواني في كتابه "إصلاح الفكر الإسلامي: مدخل إلى نظم الخطاب في الفكر الإسلامي المعاصر"، 86 تم استقرت على شكلها الأخير في دراسته "إسلامية المعرفة، بين الأمس واليوم"، 87 ولم يتجاوز العلواين المبادئ العامة التي حددها رسالة إسلامية المعرفة واكتفى بتطوير خطة العمل بناء على أن: "كتاب إسلامية المعرفة كان في جوهره بيانا للمبادئ وخطة العمل. وإذا كانت المبادئ راسخة وثابتة، فإن خطة العمل خطة اجتهادية". 88 ولكن سعي إني العلواني لتطوير خطة العمل قد اضطره كذلك لإعادة توجيه مفهوم إسلامية المعرفة بالقدر الذي يجعله منسجما مع الخطة الجديدة؛ حيث لم يعد إشكال المشروع عند العلواني يتحدد في الربط بين أزمة الأمة (التي هي أزمة فكرية في جوهرها) بالأزمة التعليمية. فالإشكال أضحى يتمثل في: "أن عالمية الأزمة (المعرفية) تتطلب عالمية الحل، وليكون الحل الإسلامي على مستوى خطاب عالمي، فإن مدخله الأساس هو "المنهجية المعرفية" القائمة على القرآن المجيد". 89

إن إسلامية المعرفة، لقيامها على قاعدة الجمع بين القراءتين، تعمل على قراءة الوحي والكون بمنهجية واحدة، انطلاقا من إطارها المعرين القائم على دعائم التوحيد ووحدة الخلق في علاقته بالخالق، ووحدة الحق ومفهومه في الوحي وفي الوجود، ووحدة الحقيقة فيهما كذلك، والجمع بين تعليل الوحي والحكمة فيه، وغائية الكون وقوانين الأسباب فيه... فإسلامية المعرفة -إذن- منهج معريف... يمثل بديلا للمادية والوضعية المتجاهلة لله وللغيب من ناحية، كما يمثل بديلا عن اللاهوتية والكهنوتية المستلبة للإنسان والطبيعة من ناحية

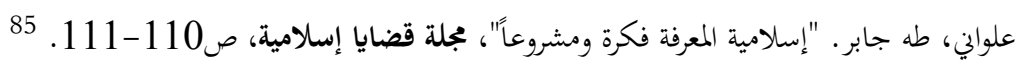
العلواني، طه جابر. إصلاح الفكر الإسلامي: مدخل إلى نظم الخطاب في الفكر الإسلامي المعاصر، فرجينيا: المعهد العالمي للفكر 86 الإسلامي، 1995.

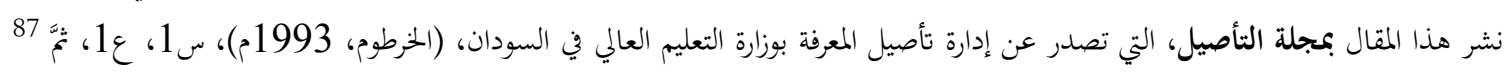

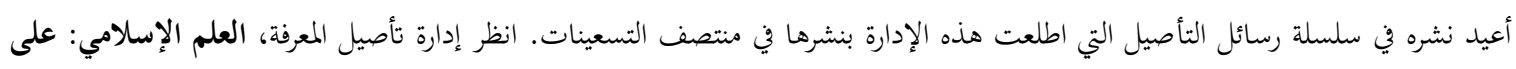

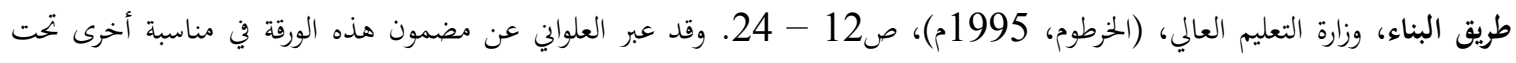

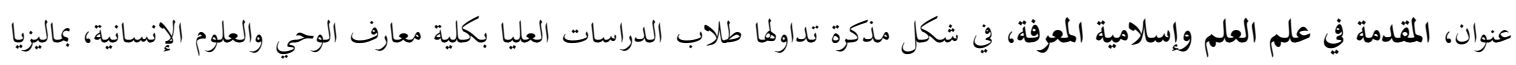

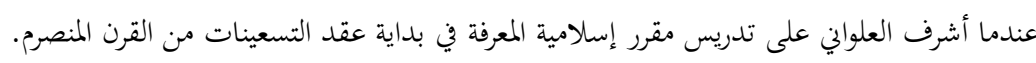

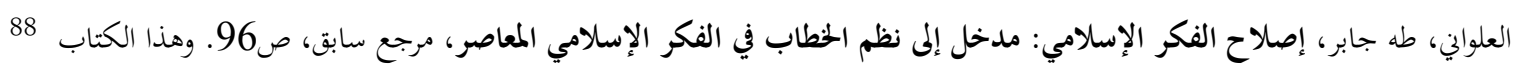

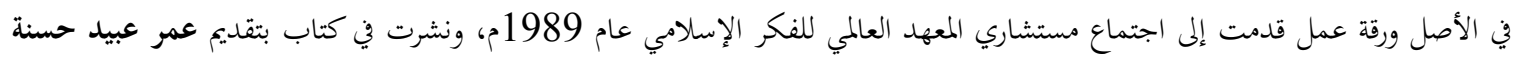

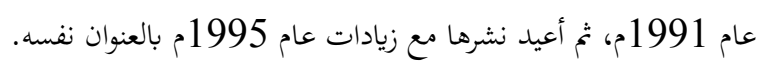

المرجع السابق، ص104. 
أخرى. 90 ولا شك في أن تعريف إسلامية المعرفة أعلاه -باعتبارها بديلا معرفيا للمادية، والوضعية، واللاهوتية، والكهنوتية- يستمده العلواني من المبررات التي ساقها حاج حمد لتركيب المعرفة على الإسلامية في مصطلح "إسلامية المعرفة"؛ حيث يقول في دراسة حديثة لخص فيها رؤيته التي ضمنها كتاباته المبكرة في إسلامية المعرفة:

[إن] نفي الوضعية عنها [أي المعرفة]... هو أساس إسلامية المعرفة، أي المعرفة الكونية غير الوضعية... فحين يسترد الدين المعرفة العلمية إليه باتجاه الكونية ويبرئها من الوضعية، يكون قد قام بعملين مزدوجين في كل واحد، فمن ناحية يدين الصراع اللاهوتي المسيحي مع العلم، ومن ناحية أخرى يدين توجهات الوضعية في العلم، فلا تكون المعرفة بعد ذاك إلا إسلامية، مُبرئا الدين من اللاهوت في ذات الوقت الذي يبرئ فيه العلم من الوضعية". 91 ولم يكن القصد من المقابلة السابقة بيان أثر حاج حمد على العلواني، وإن أمكن إظهار ذلك بصورة أوضح من خلال دراسة نصية تُعقد لمقارنة ومقاربة إسهامات العلواني المتأخرة في إسلامية المعرفة، وكتابات حاج حمد في المجال نفسه. وفي المناقشة الحالية يكفي بيان التوجهات التنظيرية التي أحدثها العلواني -على إلى وجه التحديد- في أدبيات إسلامية المعرفة، ومناقشة دلالاتما بالنسبة لمفهوم التكامل المعري. ويمكن اختصار إضافة العلواني في قضيتين، تقود أولاهما للثانية، وظل يؤكدها في أدبياته المتأخرة. القضية الأولى: يتضمنها مفهوم الجمع بين القراءتين، وتتلخص في "معرفة الصلة بين بناء النسق القرآي وبناء الكون"، شرطا ضروريا لبناء "منهجية القرآن المعرفية" التي تتثل القضية الثانية. ويذهب العلواني إلى مقابلة بين الوحي والكون انطلاقا من مبدأ أن "القرآن الكريم مكافئ في بنائه للكون"، وأن القرآن الكريم "-وحدهـالكتاب الكوني الذي يمكن اليوم أن يقدم للبشرية التصور المنهجي البديل، ويحدث حالة التجديد على مستوى عالمي، وتتم له الهيمنة بعد التصديق على مناهج هذه العلوم على النسق المعري العالمي المعاصر". 92ولعل سبب هذه المقابلة بين القرآن الكريم والكون لا يرجع فقط إلى كوغما من عند الله، بل يعود إلى علة عبر عنها حاج حمد بما نصه: "فالقراءتان ليستا متقابلتين؛ قراءة في القرآن تقابلها قراءة في الكون، وإنما هي قراءة بالقرآن عيمن على قراءة الكون المتحرك بشروطه الموضوعية". 93 ومكمن الخطورة في

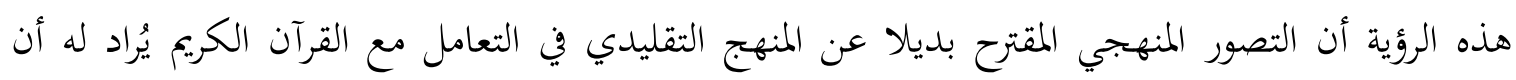
يستمد أدواته المنهجية من النسق المعرفي العالمي المعاصر - خاصة حلقة فينا ومدرسة فرانكفورت- بحجة أن بكري هذا النسق المعرفي قد بدأ يهاصر الوضعية كفلسفة للعلوم الطبيعية والإنسانية دون أن يتجاوز الإطار

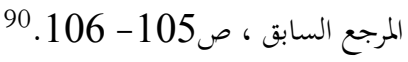

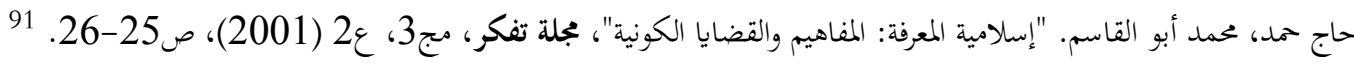

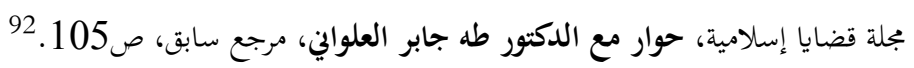

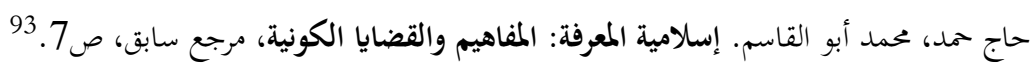


الوضعي. فتجاوز الوضعية يعني إدانة الصراع اللاهوتي المسيحي مع العلم، وإدانة التوجهات الوضعية من جهة أخرى عبر منهجية قرآنية معرفية بديلة. 94

إن المشكل الأساس -من وجهة نظرنا- بالنسبة لمنهجية القرآن المعرفية التي ينادي بها حاج حمد،

أها منهجية تعتمد على الأدوات المعرفية الحديثة لفهم القرآن وفق روحانية عرفانية ذوقية. فهذا الموقف -في الواقع- ليس في هاية التحليل إلا ارتدادا عن مبدأ إسلامية المعرفة عند روادها ومبتكري مفهومها، الداعين إلى تطوير طرائق التفكير بآليات ومناهج "الذات" و بأدوات العقل المسلم نفسه.

خاتمة:

يبدو من المناقشة السابقة لمفهوم التكامل المعرفي في الفكر الإسلامي المعاصر أن هذا المفهوم بالفعل - قد تم تداوله في المؤسسات البحثية والأكاديمية التي تبنت مشروع إسلامية المعرفة، وأن الطريقة التي تم تداول المفهومين بها توفر علاقة قوية لصيقة لا يمكن الفكاك عنها عند دراسة أيٍ من المفهومين. ولكن هذه العلاقة القوية لا يجب أن تمنعنا عن تأكيد ضرورة وأهمية الفصل بين المفهومين وتمييزها، ويمكننا - في ضوء النقاش السابق - وصف إسلامية المعرفة بأهما (رؤية) لجهد فكري منظم غايته ابتداع منهج نقدي تحليلي تركيبي يعمل على تطوير منظور توحيدي تصدر عنه كل العلوم والمعارف. فهذه الرؤية -هذذا الوصف- تمثل اليوم عند عدد من المؤسسات الإسلامية الفكرية الناشطة، مشروعا فكريا عظيما يعمل على إحياء اجتهاد فكري مدرسي مؤسسي، يتجاوز الرؤى الفردية التي تعد السمة الغالبة في البيئة الفكرية والعلمية والثقافية في العالم الإسلامي، من منطلق أن الحركة الاجتهادية الفكرية المنشودة لا بد أن تشمل جميع المعارف: القديم منها والجديد، (سواء ابتدعها المسلمون أم غيرهم). وهذه الرؤية تنبذ تقليد الموروث العلمي تقليدا حرفيا لا إبداع فيه، كما ترفض التبعية الفكرية. وإذا جاز وصف إسلامية المعرفة بأها رؤية، فإن التكامل المعرفي يجوز وصفه بأنه حالة تتسم بها العملية التعليمية في المؤسسات التربوية التي تتبنى تلك الرؤية. فالتكامل المعرفي يتسع من حيث المفهوم ليعبر عن مضامين سلوكية لا يتضمنها مفهوم إسلامية المعرفة. والناظر في الأدبيات الإسلامية المعاصرة يلاحظ أن التمييز بين المفهومين - بهذا المعنى الذي انتهينا إليه هنا- لم تتم الإشارة إليه،

إلا في حالة نادرة.

وأهمية هذا الفصل المفاهيمي بين الإسلامية والتكامل أن الإسلامية ستمثل رؤية مهيمنة على المؤسسة التربوية - التعليمية، وذلك يوفر لمخططي مناهج التعليم فلسفة إسلامية هم في حاجة حقيقية إليها،

حاج حمد، محمد أبو القاسم. منهجية القرآن المعرفية: أسلمة فلسفة العلوم الطبيعية والإنسانية، فرجينا: المعهد العالمي للفكر الإسلامي، 94 1991، ص30 32 
لضبط العملية التعليمية في ضوء البحوث العلمية المتخصصة في المناهج والتعليم. كما أن الفصل المفاهيمي، بجانب الأهمية السابقة، يسمح لشروط الرؤية الإسلامية أن تتحقق فعليا. فالوصف الذي انتهينا إليه لمفهوم إسلامية المعرفة يتطلب دراية عميقة بالمدارس الفكرية والفلسفية الحميثة، بجانب وعي عميق بالإسلام، يرتقي به الفكر الإسلامي لمواجهة المتغيرات والتحديات الحضارية المتجددة، ليستوعب ما أفضت إليه الخبرة الإنسانية في ميادين المعرفة المختلفة؛ بحيث يتم إدراجها في بنية الفكر الإسلامي على نحو يحفظ لهذا الفكر مبادئه وخصائصه التي تميزه عن غيره. ولا شك في أن مثل هذه الشروط والمواصفات لا يمكن تحقيقها دون جهٍٍ علميٍ منظم تتعهده مؤسسة تعليمية، وتحوله إلى برنامج عبر خطط عمل محددة (لإحداث هذا التكامل المنشود)، حتى يتم إتقان تلك المواصفات، وتصبح ملكة يمارس بها العالم المسلم التفكير في القضايا المعاصرة في كل مجالات المعرفة الأساسية والتطبيقية. إن المبررات التي ذكرت لتسويغ مشروع إسلامية المعرفة وتكاملها في هذه الدراسة تعكس -إذا نظرنا

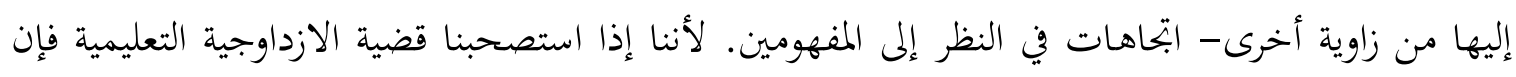
ابتاه تعريف المفهومين سينصرف لمعالجة الإشكال التعليمي؛ أما تبرير المشروع من منطلق خطر العلمانية وإشكال الخلط المفاهيمي الناتج عن مماثلة المزاعم الخاصة بالعلمنة بأوضاع الإسلام، فإنه ابتاه لتعريف المفهومين يسير ناحية المثاقفة مع الفكر الغربي؛ في حين توجه ناحية معالجة إشكال المنهجية الإسلامية وقضية التجديد في أصول المنهج. ولا شك في أن هذه الاتحاهات لها أهمية في الإصلاح الفكري المنشود، ويمكن أن تتجسد جميعها من خلال برامج عمل مؤسسات البحث العلمي والتعليم الإسلامي. لقد أظهرت الدراسة أن مفهوم الجمع بين القراءتين قد أثار جدلا وخلافا داخل مدرسة إسلامية المعرفة بسبب التصاقه بإسهامات وكتابات حاج حمد، الذي يطمح إلى بناء منهجية قرآنية معرفية من خلال الاعتماد على الأدوات المعرفية الغربية. فمشروع إسلامية المعرفة أصلا هو في جوهره - كما مر بنا- اعتراض على الاقتراب المنهجي، ونبذ للتفكير النظري المجرد الذي لا يتصل بالواقع.

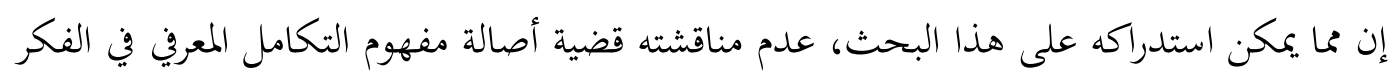
الإسلامي المبكر. وهو أمر يستحق دراسة مستقلة. ويكفي في هذا المقام أن نشير إلى أن معظم الإجابات التي توصلنا إليها من المقابلات التي أجريناها مع عدد من الناشطين في إسلامية المعرفة، تستحضر حال

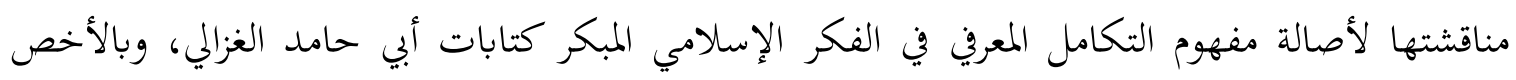
كتابه إحياء علوم الدين، وابن رشد حول فصل المقال، وابن تيمية في موضوع درء تعارض العقل والنقل. وجل المعاصرين الذين استحسنوا هذا المفهوم ينطلقون من حقيقة أن القرآن - كما يقول النشار 95- قد رسم للناس عامة قواعد الفكر والنظر إلى جانب قواعد الحياة العملية، وأنه قد اشتمل على تصور فهائي للكون

النشار، على سامى، نشأة الفكر الفلسفي في الإسلام، مرجع سابق، ص2-3. 95 
(ميتافيزيقي)، وأنه قد وضع قواعد السلوك الإنساني (الأخلاق)، وأنه لم يترك جانبا من جوانب الفكر والعمل

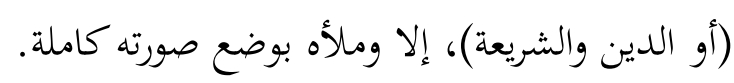

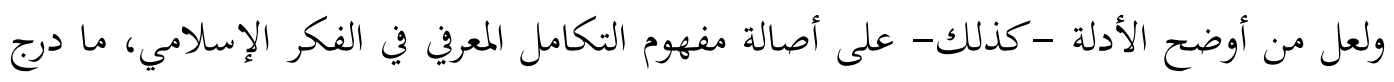

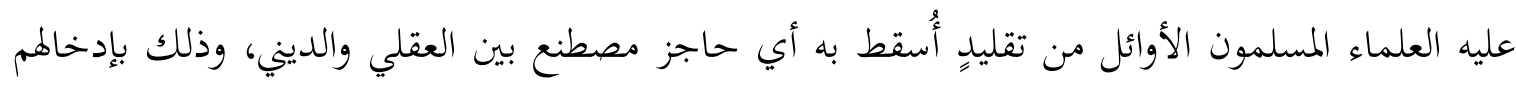

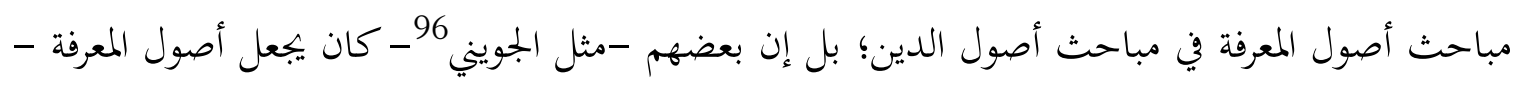

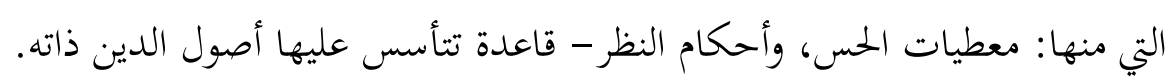

الجويني، أبو المعالي عبدالملك، الإرشاد إلى قواطع الأدلة في أصول الاعتقاد، تحقيق أسعد تميه، بيروت: مؤسسة الكتب الثقافية، 1985، 96 ص 